\title{
LOS MOLINOS DEL YACIMIENTO DEL CERRO DE LA CRUZ (ALMEDINILLA, CÓRDOBA): CLASIFICACIÓN Y ANÁLISIS DE LOS EJEMPLARES DE ÉPOCA IBÉRICA Y EMIRAL
}

\author{
GRINDING MILLS FROM THE SITE AT 'CERRO DE LA CRUZ' (ALMEDINILLA, CÓRDOBA). \\ CLASSIFICATION AND ANALYSIS THE IRON AGE AND ISLAMIC EXAMPLES
}

\author{
FERNANDO QUESADA SANZ* \\ EDUARDO KAVANAGH DE PRADO* \\ MERCEDES LANZ DOMÍNGUEZ*
}

\begin{abstract}
Resumen: En este trabajo damos a conocer los molinos hallados en el yacimiento del Cerro de la Cruz (Almedinilla, Córdoba) correspondientes a los dos periodos de ocupación documentados en el yacimiento: ibérico tardío (s. II a.C.) y emiral final o califal inicial (siglos IX-X d.C.). Se presenta una clasificación y se discuten las posibles implicaciones de tipo socio-cultural que se pueden deducir del análisis y distribución urbana de este tipo de objetos.

Palabras Clave: molinos, grano, tecnología, Cultura Ibérica, Periodo emiral
\end{abstract}

\section{CONSIDERACIONES SOBRE LOS MOLINOS DE LA EDAD DEL HIERRO, SU CLASIFICACIÓN Y CRONOLOGÍA}

Con un elevado grado de simplificación, podemos distinguir dos grandes grupos de molinos en época antigua: de vaivén y rotatorios o rotativos. En el primer

* Departamento de Prehistoria y Arqueología, Facultad de Filosofía y Letras, Universidad Autónoma de Madrid, 28049 Madrid. Correo-e: fernando.quesada@uam.es; eduardo.kavanagh@gmail.com; mercedes.lanz.dominguez@gmail.com

\begin{abstract}
In this paper we discuss grinding mills from the archaeological site at El Cerro de la Cruz (Almedinilla, Corduba, Spain). They belong to the two periods identified and documented at the site: Late Iberian (mid $2^{\text {nd }}$ cent. BC) and the final years of the Emirate of Corduba or the first years of the Caliphate (late $9^{\text {th }}$-early $10^{\text {th }}$ cent. AD). We present a classification and discuss the potential social and economic implications that we may obtain from the analysis and urban distribution of these objects.
\end{abstract}

Key words: Grinding mills, grain, technology, Iron Age, Iberian Culture, Cordoba emirate.

grupo, obviamente más primitivo, el movimiento es realizado por una moledera agarrada con las manos que fricciona sobre una superficie fija plana, movimiento que produciría un desgaste característico a la parte pasiva o de la tabla. En el Cerro de la Cruz (Almedinilla) hemos podido documentar dos molinos de vaivén ( $n^{\circ}$ cat. 15 y 16). Uno de ellos ( $n^{\circ}$ cat. 15 ) es un fragmento hallado en un nivel superficial (A) de las excavaciones de 1987 (zona G12), sobre el espacio de la habitación I (=XVIII), asociado a cerámica ibérica y medieval. El otro ( $\mathrm{n}^{\circ}$. cat. 16), más completo, apareció en superficie fuera de la zona excavada $y$, por tanto, sin 


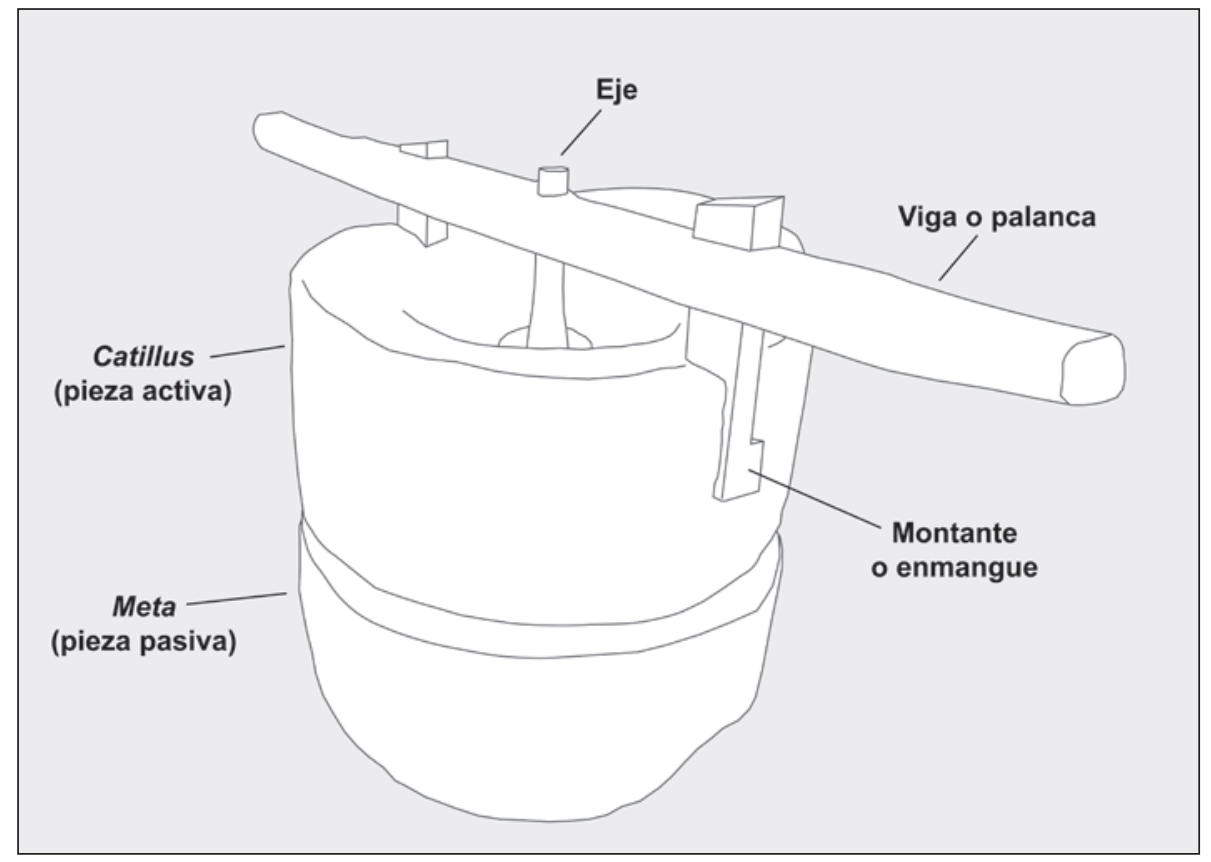

Figura 1. Reconstrucción de molino rotatorio correspondiente a uno de los ejemplares hallados en el Cerro de la Cruz (no. 24/25 en nuestro catálogo) con indicación de la nomenclatura usada en el texto. contexto arqueológico preciso. En todo caso, no es del todo descartable la pervivencia ocasional de molinos de vaivén en la época ibérica más tardía, dado que este es un fenómeno documentado para el s. V a.C. en el yacimiento del Tossal del Moro (Arteaga y Padró 1990: 136) y para el s. III a.C. en el yacimiento de Mas Castellar de Pontós (Pons y García 2008: 172) (vid. infra). En todo caso, y aunque es tema importante para el que existen estudios significativos (especialmente Alonso 1996, 1999), la cuestión de la pervivencia de los molinos de vaivén y su progresiva sustitución por el modelo rotatorio es tema complejo sobre el que existe amplia bibliografía reciente y en el que no debemos entrar en este estudio, de alcance mucho más concreto. Un buen ejemplo de la complejidad de estas cuestiones puede hallarse en el caso de 'La Mata de Campanario' (Badajoz), donde la presencia de molinos barquiformes de vaivén de gran tamaño puede asociarse a estructuras de soporte (estancias 2 y 7), normalmente consideradas características de molinos circulares (Rodríguez et al. 2004 passim, espec. 208ss. y 271ss.).

Sea como fuere, en el Cerro de la Cruz la casi totalidad de los molinos y todos los hallados en contexto son de tipo rotatorio. La cuestión sobre el origen cronológico y geográfico de este tipo es objeto de un debate intenso, abierto hace años, y que todavía continúa. Lejos de pretender iniciar una nueva línea de discusión sobre dicho origen, por ahora recordaremos que si hace dos décadas la documentación existente era «más bien escasa y lo que es más importante, dispersa, particular y fragmentaria» (Escalera y Villegas 1983: 15), la situación cambia rápidamente, como se deduce sobre todo de los trabajos de Natalia Alonso (1996, 1997, 1999,2000 y 2004) o de los de otros autores (Berrocal 2006), que nos permiten conocer las distintas visiones e hipótesis sobre el origen de los molinos rotatorios así como su dispersión por todo el Mediterráneo.

El molino rotativo o rotatorio se caracteriza por constar de dos piezas de piedra de forma circular y sección variada, encajadas entre sí por planos inclinados y enlazadas por un eje vertical, de forma que la inferior (meta o pieza pasiva) permanece estática mientras que la superior (catillus o pieza activa) rota apoyada sobre la anterior. La pieza activa puede presentar una, dos o más muescas en los laterales exteriores, destinadas al enmangue de unos elementos de madera que facilitan el movimiento del conjunto. Para ello se ajustaría un eje vertical, entendemos que de madera por no haberse encontrado otros restos, embutido en el ojo u orificio central de la meta (Guérin 1999: 89). Por su parte, la pieza activa recibiría dos o más vástagos verticales (montantes) encajados en muescas hechas a tal efecto en sus laterales. Finalmente, tanto el eje como los montantes se afianzarían a una viga o palanca horizontal que permitiría el giro de la pieza activa (catillus) (fig. 1).

Algunos autores han considerado que este tipo de movimiento sólo podía ser ejecutado por dos personas (Borges 1978: 120). Se ha discutido incluso si el trabajo 


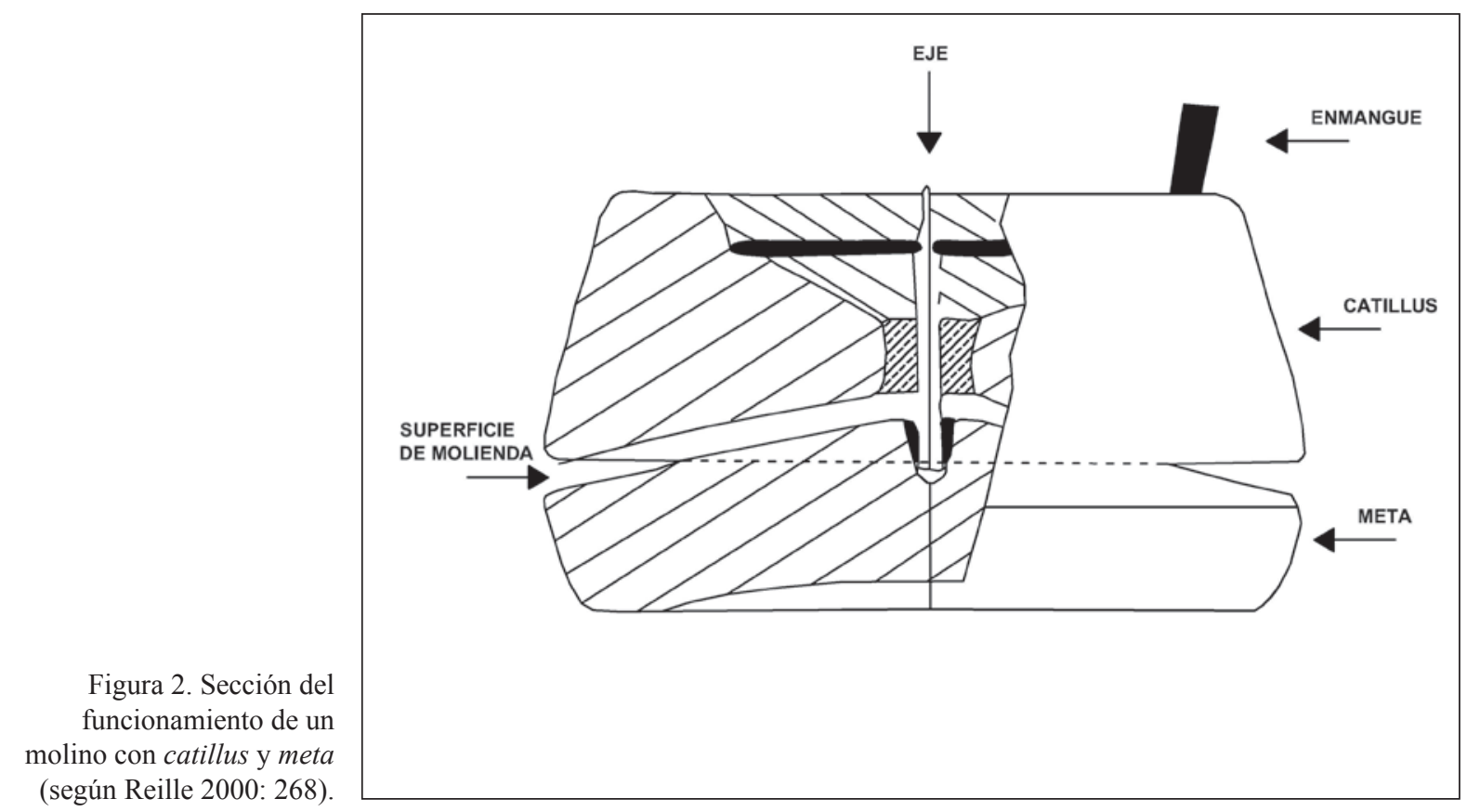

en estos molinos manuales sería ejecutado por mujeres (vid. Moritz 1958: 111; Alonso 1999: 234). En el caso de los molinos que cuentan con una sola muesca de enmangue, la acción de rotación se ejecutaría mediante un brazo de madera inserto verticalmente en el catillus, ejecutando quizá un movimiento semirrotativo de $180^{\circ}$ en vaivén. Un factor que puede orientarnos sobre si un molino se utilizó con un movimiento de rotación completa o de semi-rotación puede ser su disposición respecto a objetos o estructuras cercanas o inmediatas que determinen el espacio disponible.

Ante la ausencia de evidencia en sentido contrario, estimamos que el conjunto de los molinos del Cerro de la Cruz estaría destinado a la transformación del grano con fines alimenticios, tal y como es evidente por la presencia de semillas y harina carbonizada junto a alguno de ellos (vid. infra). Para otros yacimientos también se ha propuesto que su uso fuera distinto a éste, acaso vinculados a tareas metalúrgicas (Risch 1995: 163).

No existe todavía ninguna propuesta de tipología general que organice y articule el conjunto de los molinos rotativos del mundo ibérico y, menos aún, el conjunto de los de ámbito protohistórico ya que la mayoría de los estudios son clasificaciones adaptadas al material hallado localmente, lo que dificulta su aplicación a otros conjuntos. Entre las tipologías más destacadas podemos señalar la que realizara Fernández de Avilés, quien llegó a catalogar un total de 406 ejemplares
(Berrocal 2006); los extensos y completos trabajos de Natalia Alonso (1996, 1997, 1999, 2000 y 2004), los trabajos de $\mathrm{M}^{\mathrm{a}}$ Teresa Genis (1985 y 1986) para el yacimiento de Ullastret o los de Asensio para el yacimiento de Alorda Park (Asensio et al., 2000-01).

Entre los trabajos realizados fuera de España destacaremos especialmente la obra de Py (1992) para los molinos de Lattes, cuyo criterio de clasificación es de los más concretos, la obra de Borges (1978) para los molinos de Conimbriga y el reciente y voluminoso trabajo de Longepierre (2012) para la Galia meridional, en el que, sin embargo, se aprecia también una atenta mirada al escenario peninsular.

La dificultad de ajustar la cronología a los molinos se debe a que se trata de piezas o herramientas que no sufrieron muchos cambios en varios siglos, dado que el mecanismo para la molienda seguía siendo básicamente el mismo. No son pocas las menciones a la escasez de estudios sobre los molinos y la dificultad de ajustar una cronología basada solamente en su tipología y no por su contexto. Para M. Py (1992: 195), los molinos del tipo rotativo bajo (B1 según su tipología) serían los rotativos más antiguos de Lattes, situándose en el siglo III a.C. Sin embargo, los molinos rotatorios de tipo bajo que se engloban en una tipología más amplia son, para este autor, ampliamente conocidos en el Mediterráneo ya desde el siglo IV a.C. Según Amouretti (1986: 246), los molinos rotativos manuales se documentan de forma esporádica ya en el siglo IV a.C. y, de 
forma profusa, desde fines del III a.C., aunque estudios más recientes remontan su origen a fecha tan temprana como el siglo V a.C. (Alonso 1999: 241, 243, 251, 255, Longepierre 2012: 103). Tanto unos como otros coinciden en identificar la península ibérica como lugar de origen de este tipo de molino (rotatorio).

Sin lugar a duda los primeros molinos atestiguados son los de vaivén, puesto que el molino rotatorio supuso una gran evolución técnica. En algunos yacimientos, la perduración de este tipo de molinos primitivos es larga (Alonso 2000: 134), llegando a usarse incluso hasta finales del s. III a.C. (Junyet y Baldellou 1972: 57) e, incluso, quizá más allá, como podría apuntar el Cerro de la Cruz. Es común a muchos yacimientos que los dos tipos convivan a lo largo de los siglos, documentándose el rotativo desde el s. V a.C., en paralelo con el naviforme hasta por lo menos el s. III a.C. (Pons y García 2008: 173). Sin embargo, en otros yacimientos como Els Vilars, se localizan molinos rotatorios en contextos tan tempranos como el final del s. VI a.C. (Alonso 1995: 16, 2004: 117), muy anteriores a otros yacimientos, posible indicio del origen peninsular de este modelo antes de su difusión hacia el Mediterráneo central (Alonso 1997: 18). En el poblado de Penya del Moro (St. Just Desvern) se han documentado dos molinos rotatorios fechados entre los siglos $\mathrm{V}$ e inicios del IV a.C. (citados por Arteaga en la publicación de Pinyeres, $c f$. además Alonso 1995: 17). En este caso, se ha planteado que su introducción vino determinada por el proceso de iberización de la comarca y como resultado de la llegada de gentes ibéricas procedentes de las regiones situadas más al este (Arteaga et al. 1990: 136). También se datan en torno a la segunda mitad del s. V a.C. ejemplares rotatorios en el poblado ibérico de Puig de la Nau (Oliver y Gusi 1995:183). La difusión del molino rotatorio es, sin embargo, aparentemente desigual, habiendo casos en los que su presencia no se documenta hasta la segunda mitad del s. III a.C., como sucede en el yacimiento de Más Castellar de Pontos (Pons y García 2008: 173).

\section{CLASIFICACIÓN DE LOS MOLINOS DEL CERRO DE LA CRUZ}

El análisis del registro documental hallado en el yacimiento de El Cerro de la Cruz (fig. 3) nos permite identificar una serie limitada de tipos, seis en total, con algunas variantes. Salvo el primer modelo, todos se corresponden con molinos rotatorios formados por dos piezas, una activa y otra pasiva. En tales casos, la tipología viene definida por la forma del catillus, siendo la meta clasificada en relación con su catillus correspondiente en los casos en que conservamos ambas piezas. A semejanza de otros autores que han trabajado estos objetos, el catálogo que ofrecemos a continuación ha sido elaborado exclusivamente para catalogar los molinos del Cerro de la Cruz. Como se ha indicado anteriormente, nos hemos basado en clasificaciones similares diseñadas para otros yacimientos, lo que nos ha permitido establecer una serie de paralelos.

Tipo 0: Modelo de molino perteneciente al grupo de los denominados "barquiformes" o "naviformes". Se documentan dos ejemplares en el yacimiento.

Tipo A: Molino rotatorio formado por dos piezas, una activa (catillus) y otra pasiva (meta). La pieza pasiva suele tener una parte baja (en contacto con el suelo) cilíndrica, que continúa en forma cónica con lados cóncavo-convexos o casi rectos. La pieza activa muestra la cara exterior vertical y una sección triangular. El catillus presenta profundas muescas verticales de sección cuadrangular para acoger el enmangue de madera, que partiría de la parte superior. En este tipo la superficie de fricción la parte inferior del catillus tiene una curvatura variada para adaptarse a la meta, que varía según el subtipo.

Dentro de este modelo hemos identificado las siguientes variantes:

A1: Variante con dos escotaduras o muescas laterales diametralmente opuestas, talladas en la parte superior del catillus pero sin llegar a recorrer por completo su cara exterior. A veces, la escotadura se dobla ligeramente en ángulo recto en la parte inferior, en forma de "L" hacia un lado, no hacia el interior.

A2: Modelo en el que las dos muescas de enmangue laterales recorren verticalmente la altura del catillus desde la parte superior a la inferior.

A3: Modelo cuyo catillus cuenta con cuatro muescas de enmangue dispuestas en dos parejas, diametralmente opuestas. La primera pareja es visible desde la parte superior $\mathrm{y}$, como en A1, recorre los dos tercios de la altura del catillus sin llegar a la parte baja. A menudo, esta escotadura se dobla en ángulo recto en la parte baja. La segunda pareja de escotaduras arranca desde la parte inferior $y$, por tanto, no es visible desde arriba y es mucho más corta. No se cruza en ángulo recto con la primera pareja sino que la línea diametral ideal que la une rota unos $30^{\circ}$ respecto a la de aquella (fig. 3). 


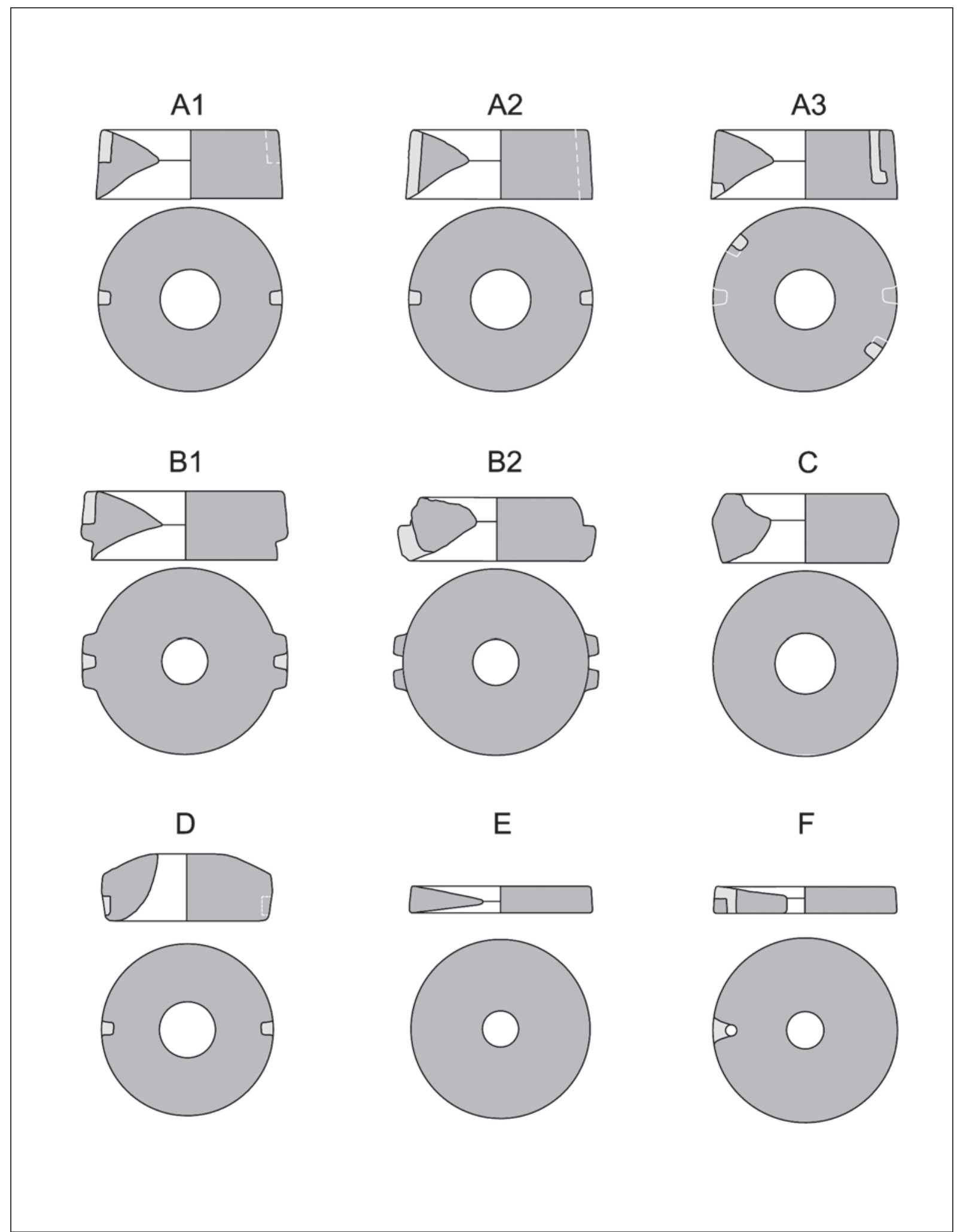

Figura 3. Clasificación de los molinos hallados en El Cerro de la Cruz. El tipo E es de tipo romano, y el F corresponde a la fase medieval andalusí. A partir de la pieza hembra o catillus. 
Tipo B: Es similar al modelo anterior con la diferencia de que en este caso se soluciona la necesidad de enmangue del catillus, no con muescas rehundidas en la piedra mediante tallado sino con salientes, muñones $\mathrm{u}$ orejetas que sobresalen a ambos lados del catillus. Estos apéndices están destinados a servir de asiento o encaje para los enmangues de madera, para el movimiento de rotación de la pieza. Adicionalmente, en este tipo la superficie de fricción, en la parte inferior del $c a$ tillus suele presentar lados de tendencia marcadamente cóncava.

En función del número de apéndices identificamos dos variantes:

B1: Modelo dotado de dos grandes apéndices dispuestos en los laterales del catillus. El interior de cada uno de ellos muestra una muesca o acanaladura vertical en forma de " $\mathrm{T}$ " invertida, destinada a acoger los enmangues que no abarca toda la altura del catillus.

B2: Modelo dotado de apéndices dispuestos en parejas, pero las muescas verticales recorren toda la altura de la pieza, dejando sendos pares de orejetas.

Tipo C: Similar al tipo A pero dotado de una muy marcada concavidad en la parte superior de la pieza, quizá destinada a facilitar el vertido del grano en el interior del molino. El mal estado de conservación de los ejemplares documentados nos impide precisar el método de enmangue en este modelo y, por lo mismo, el tipo tiene carácter provisional, que eventualmente podría integrarse como variante del Tipo A.

Tipo D: La cara superior del catillus, en lugar de ser rehundida hacia el interior (lo que facilita el vertido del grano) como en los tipos A, B o C, es -por el contrarioplana o incluso vierte hacia el exterior y no el interior. El catillus cuenta con acanaladuras laterales de enmangue que parten de la parte inferior pero no la recorren en toda su altura.

Tipo E: Molino rotatorio documentado en un único ejemplar, cuya sección de catillus tiende a ser triangular muy aplanada. La característica definitoria de este molino es la desproporción entre el escaso grosor y el diámetro tanto de la meta como del catillus, lo que supone que el conjunto muestre un aspecto más 'plano'. Creemos que se trata de un modelo de tipología ya romana republicana, como parecen sugerir algunos paralelos documentados. Así sucede con algunos casos de molinos rotatorios romanos referidos por Gudea (1997: variantes I.1.c y I.2.a) y destacadamente por Py
(1992: 203-204). En este último caso la semejanza de nuestro ejemplar con los modelos pertenecientes a la tipología "B2e" de este autor creemos basta para clasificarlo como tal. La cronología de este último modelo es 150-125 a.C. coincidente con la cronología del Cerro de la Cruz (ca. 140 a.C.). Quizá se trate de una pieza procedente de la zona de la campiña o incluso de la vega del Guadalquivir. La cronología propuesta por Py para un modelo muy similar de tipo de molino data del 150-125 a.C. (Py 1992: 204). El catillus podría contar con una muesca horizontal lateral, aunque la conservación parcial del perímetro de la pieza nos impide afirmarlo con rotundidad.

Tipo F: Modelo que tanto por su tipología como por los contextos de hallazgo, parece corresponder a una cronología medieval emiral. Se trata de un molino rotatorio formado por dos piezas, activa y pasiva. El catillus muestra una sección rectangular, no triangular como en el tipo E. La superficie de la meta (y por tanto de fricción) es plana, siendo ésta la característica definitoria del tipo.

El tamaño de los molinos y, a partir de éste, su manejo puede ser calculado mediante criterios múltiples. El más sencillo, pero no por ello menos eficaz, es el de su diámetro exterior (fig. 17): Se aprecia en ese sentido que la mayoría de los molinos de tipo A, oscila en torno a los 51-58 cm de diámetro, un tamaño respetable pero no excesivo para lo que se conoce en otros yacimientos ibéricos. Un segundo grupo, más variado tipológicamente, oscila en torno a los $35-38 \mathrm{~cm}$. Las piezas menores, en torno a los $30 \mathrm{~cm}$, son las de tipo B. Los molinos planos de tipo romano (F) y los andalusíes medievales son más pequeños y mucho menos pesados que la mayoría de los ibéricos.

En conjunto, los molinos ibéricos de tipo B y D y también los medievales de tipo F del Cerro de la Cruz son molinos rotatorios manuales y no 'de sangre' si se entiende por tales los movidos por animales o por personas trabajando en pie ( $v$. infra).

Más complejo es el caso de la mayoría de los ejemplares, mucho mayores $(50-60 \mathrm{~cm})$. La opinión generalizada es que por su tamaño, demasiado grande para realizar una rotación completa para una sola persona en posición sentada/acuclillada/de rodillas, estos molinos serían 'de sangre'. Es la opinión de muchos autores (entre los últimos, Anderson 2011, Longepierre 2012: 77-78 y 86-87), para quienes por razones anatómicas humanas los molinos manuales no sobrepasan nunca los $40 \mathrm{~cm}$ de diámetro (nuestros 
tipos B y D), mientras que los que se articulan en torno a los $55 \mathrm{~cm}$ (nuestro tipo A) serían según su criterio siempre de sangre, movidos por un hombre en pie o un animal.

En el Cerro de la Cruz, el espacio donde se ubican los molinos y la altura de las plataformas no permite tal cosa, por lo que incluso los molinos de $50-60 \mathrm{~cm}$ debieron ser movidos quizá por dos personas en posición acuclillada o de rodillas, lo que no deja claro si deben ser insertados en una u otra categoría.

Los ojos de los molinos, destinados al eje vertical, pueden ser en el Cerro de la Cruz de forma circular (número de catálogo 21), o cuadrada, con rebajes (n. cat. 6) o sin ellos (n.cat. 24/25). La alternancia de ojos cuadrados y redondos se da en otros muchos contextos (Castella y Anderson 2004: figs. 15-16). En algún caso, hemos podido documentar el uso de láminas de plomo embutidas en el ojo para asegurar el enmangue de las piezas de madera, como en el molino 24/25 (vid. figs. 1, 4 y 11).

La mayoría de los molinos del Cerro de la Cruz (ver catálogo para otros casos) se tallaron en toba calcárea porosa o 'travertino', o de similar roca carniola sedimentaria (Anderson 2011), cuyos mejores paralelos se encuentran en el cercano Museo Arqueológico de Priego de Córdoba, lamentablemente sin contexto arqueológico preciso (Anderson 2011). Indicio de la fabricación local de las piezas $-\mathrm{o}$ de la mayoría de ellas- puede ser, aparte del empleo de piedra de la comarca, el que alguna esté inacabada, caso de n.cat. 18.

\section{CATÁlogo}

En el presente catálogo de piezas (tabla 1, figs. 4 a 9) hemos numerado los ejemplares por piezas conservadas (no necesariamente por fragmentos, cuando varios trozos forman parte de la misma meta o del mismo catillus comparten el número de catálogo). De este modo, meta y catillus de un mismo molino llevan dos números distintos en el catálogo, sin perjuicio de que se estudien conjuntamente en aquellos casos cuya asociación es indudable, indicando la asociación mediante una barra (i.e. 26/27).

El material usado para la fabricación de los ejemplares del Cerro de la Cruz es, en la mayoría de los casos, piedra caliza, toba calcárea (o travertino), muy fácil de trabajar. Excepciones a esta norma son los ejemplares $\mathrm{n}^{\mathrm{o}}$ cat. 7 , de piedra granítica, el $\mathrm{n}^{\mathrm{o}}$ cat. 11 , de arenisca, y los $n^{\circ}$ cat. 15 y 16 , de identificación pendiente.

\section{Tipo 0 (naviforme o barquiforme)}

\section{$\mathbf{N}^{\circ}$ CAT. 15 (fig. 9)}

Tipo: Parte pasiva de molino naviforme.

Dimensiones: Longitud indeterminada; ancho superficie fricción indeterminado pero estimado en $30 \mathrm{~cm}$; grosor de la pieza estimado en $8.5 \mathrm{~cm}$

Material: Piedra oscura densa y pesada de grano fino ¿basáltica?

Estado: Menos del 25\%. Muy rodado.

Tipología: Fragmento de molino naviforme del que se distingue claramente la parte superior o de fricción. No se ha localizado la pieza activa.

Localización/observaciones: G12, Bolsa 7, contexto a. Sobre estancia XVIII. Hallado en niveles superficiales (contexto a) y en asociación con material cerámico ibérico y medieval, lo que nos invita a pensar en una cronología igualmente medieval, aunque sin seguridad.

Datación: Indeterminada, posiblemente medieval.

\section{$\mathrm{N}^{0}$ CAT. 16 (fig. 9)}

Tipo: Parte pasiva de molino barquiforme.

Dimensiones: Longitudinal: $38.50 \mathrm{~cm}$; ancho superficie fricción: $21.60 \mathrm{~cm}$; grosor de la pieza: $11.60 \mathrm{~cm}$. Material: Piedra negra densa y pesada ¿basalto?

Estado: Más del 50\%. Bien conservado

Tipología: Parte pasiva de un molino naviforme. No se ha localizado la pieza activa.

Localización/observaciones: Hallado en superficie en el camino de acceso al yacimiento. Procedencia exacta desconocida.

Datación: Indeterminada, pudiendo ser ibérica o emiral-califal.

\section{Tipo A}

$\mathbf{N}^{\circ}$ CAT. 1 (fig. 4)

Tipo: Catillus

Dimensiones: Diámetro exterior: $50.68 \mathrm{~cm}$. Diámetro interior (= diámetro del ojo): $17.22 \mathrm{~cm}$.

Material: Caliza/travertino

Estado: Menos del 25\% del diámetro. Muy rodado.

Tipología: Pertenece al tipo A. No podemos precisar la variante ya que el mal estado de conservación nos impide identificar vestigio de muesca o enmangue alguno.

Localización/observaciones: Tres fragmentos. F13/14, estancia $\mathrm{O}$, contexto "c". Piezas de un mismo catillus, halladas en el interior del aljibe ibérico.

Datación: Siglo II a.C. 


\section{No CAT. 3 (fig. 4)}

Tipo: Catillus

Dimensiones: Diámetro exterior: incierto (el mal estado de conservación nos impide determinarlo). Diámetro interior: $c a .25 \mathrm{~cm}$.

Material: Caliza/travertino.

Estado: Menos del 25\%. Muy rodado, pero se observa bien una de las muescas del enmangue.

Tipología: Tipo A.

Paralelos: La forma general, inclinación de la superficie de fricción y muesca lateral son características propias de un número amplio de molinos de cronología y adscripción cultural ibérica, cuya cronología se estima genéricamente en torno a los siglos V-I a.C. (Longepierre 2012: 103, Alonso y Martínez 1999: passim, Asensio et al. 2000-2001: 68, planche 5 y $2 \mathrm{a}$, entre otros).

Localización/observaciones: Localización original desconocida.

Datación: Mediados del siglo II a.C.

\section{No CAT. 26/27 (fig. 8)}

Tipo: Meta y catillus

Dimensiones de la meta: Diámetro exterior: $52,5 \mathrm{~cm}$. Diámetro del eje central: $5 \mathrm{~cm}$. Profundidad del ojo: $4.88 \mathrm{~cm}$, área de fricción: $2166 \mathrm{~cm}^{2}$.

Material: Caliza/travertino.

Estado: Casi 100\%. Meta hoy fragmentada en su base y parcialmente erosionada en su apéndice superior.

Tipología: Pertenece al tipo A.

Paralelos: Similar al caso anterior (vid. entrada anterior).

Localización/observaciones: Molino completo (meta y catillus) hallado in situ en la estancia ibérica AI (= e Estancia II), J15/W, contexto 'b', asociado a ánforas ibero-púnicas y otro catillus igualmente ibérico (cat. $\mathrm{n}^{\mathrm{o}}$ 7). El reducido espacio de la estancia prueba que estos molinos estaban almacenados, y no en uso, pues no hay espacio suficiente en derredor suyo para trabajar. Es posible en todo caso que provenga del derrumbe del piso superior o azotea.

Datación: Mediados del siglo II a.C.

\section{Tipo A1}

No CAT. 21/22 (fig. 4)

Tipo: Molino completo formado por catillus $\mathrm{n}^{\mathrm{o}}$ cat. 22 y meta $\mathrm{n}^{\mathrm{o}}$ cat. 21 .

Dimensiones: Diámetro exterior: $59 \mathrm{~cm}$, diámetro del eje central: $5.86 \mathrm{~cm}$. Profundidad del oído indeterminada ya que la cima está erosionada. Área de fricción: $2712 \mathrm{~cm}^{2}$.
Material: Caliza/travertino.

Estado: Casi completo

Tipología: Tipo A1.

Paralelos: Se corresponde con el modelo R2 A1 de Alonso, documentado en los niveles III-IV de Els Vilars (Arbeca, Garrigues, Cataluña), esto es, a partir del siglo IV a.C. (Alonso 1999: 243, 253, fig. 163). También en Molí del Espigol (Tronabous, Pla d'Urgell, Cataluña), en contextos datados en un periodo comprendido entre fines del s. IV a.C. y el 200 a.C. (Alonso 1999: 254).

Localización/observaciones: Molino hallado in situ, tanto su pieza activa como pasiva. La pieza activa (catillus $\mathrm{n}^{\circ}$ cat. 22) aparece fragmentada en torno a su pieza pasiva (meta $\mathrm{n}^{\circ}$ cat. 21). El catillus no ha sido dibujado ya que su excavación permanece inconclusa. Asociado a ánfora grecoitálica del siglo II a.C.

Datación: Mediados siglo II a.C.

No CAT. 24/25 (fig. 4)

Tipo: Molino completo, formado por meta $\left(\mathrm{n}^{\circ}\right.$ cat. 24$) \mathrm{y}$ catillus ( $\mathrm{n}^{\mathrm{o}}$ cat. 25$)$.

Dimensiones: Diámetro exterior $55 \mathrm{~cm}$, altura total (meta+catillus): $59 \mathrm{~cm}$; altura parte cilíndrica de la meta: 28/30 cm; atura del catillus $33 \mathrm{~cm}$.

Material: Caliza/travertino

Estado: Completo.

Tipología: Tipo A1

Paralelos: Vide entrada anterior.

Localización/observaciones: L15, Estancia AB, contexto 'an'. Molino completo hallado in situ en la estancia AB sobre plataforma de piedra y adobe. Llama la atención la presencia de lámina de plomo en torno al oído de la meta, para lograr una fijación más sólida entre la meta y eje del molino. Actualmente en exposición en el Ecomuseo del Río Caicena.

Datación: Mediados del siglo II a.C. Asociado a F68 L de Camp. A y moneda Jano/proa del s. II a.C.

\section{Tipo A2}

\section{No CAT. 4 (fig. 5)}

Tipo: Catillus.

Dimensiones: Diámetro exterior: $34.7 \mathrm{~cm}$, diámetro interior: $8.4 \mathrm{~cm}$.

Material: Caliza/travertino.

Estado: Buena conservación de en torno al 50\%, con superficie de fricción claramente visible.

Tipología: Tipo A2 similar al modelo A pero diferenciado de este en la característica de que la muesca 
Tabla 1. Columna de situación: In situ (hallado en el lugar de trabajo); Desplazado (hallado en excavación pero aparentemente desplazado de su ubicación original (reubicaciones y reutilizaciones); Descontextualizado (desconocemos su localización original).

\begin{tabular}{|c|c|c|c|c|c|c|}
\hline $\mathrm{N}^{\circ}$ Cat. & Pieza & Tipo & UE & Cuadrícula & Situación & Estancia/muro \\
\hline 1 & Catillus & Tipo A & $\begin{array}{c}\text { Contexto c } \\
\text { (Bolsa 12.68) }\end{array}$ & F13/F14 & Desplazado & Estancia O \\
\hline 2 & Catillus & Tipo A o D & - & - & Descontx. & - \\
\hline 3 & Catillus & Tipo A & - & - & Descontx. & - \\
\hline 4 & Catillus & Tipo A2 & - & - & Descontx. & - \\
\hline 5 & Catillus & Tipo A3 & Contexto b & F14 & In situ & Estancia O \\
\hline 6 & Meta & Tipo A3 & Contexto $\mathrm{b}$ & F14 & In situ & Estancia O \\
\hline 7 & Catillus & Tipo B1 & $\begin{array}{l}\text { Contexto g } \\
\text { (Bolsa 83) }\end{array}$ & $\mathrm{J} 15-\mathrm{W}$ & In situ & Estancia AI(=II) \\
\hline 8 & Catillus & Tipo B2 & US1295 & K13 & Desplazado & $\begin{array}{l}\text { Estancia XIV (entre los muros } \\
\text { UC1213; UC1317; UC1199). }\end{array}$ \\
\hline 9 & Catillus & Tipo C & - & - & Descontx. & - \\
\hline 10 & Catillus & Tipo D & - & - & Descontx. & - \\
\hline 11 & Catillus & Tipo F & 1004 (Bolsa 081) & I11 & Desplazado & $\begin{array}{c}\text { Estancia } 1 \text { medieval, sobre el es- } \\
\text { pacio VI }\end{array}$ \\
\hline 12 & Catillus & Tipo F & 1026 & $\mathrm{I} 12$ & Desplazado & Medieval. Estancia V-IV \\
\hline 13 & Catillus & Tipo E & 1034 (Bolsa 178) & $\mathrm{I} 14$ & Desplazado & Estancia XXII-XXIV \\
\hline 14 & Meta & Tipo E & 1034 (Bolsa 178) & $\mathrm{I} 14$ & Desplazado & Estancia XXII-XXIV \\
\hline 15 & Naviforme & Tipo 0 & $\begin{array}{l}\text { Contexto a } \\
\text { (Bolsa 7) }\end{array}$ & G12 & Desplazado & Estancia XVIII (I) \\
\hline 16 & Naviforme & Tipo 0 & - & - & Descontx. & - \\
\hline 17 & Meta & Tipo A, B, C o D & US 1020 & $\mathrm{I} 12$ & In situ & Estancia V \\
\hline 18 & Catillus & Tipo A, B, C o D & US 1161 & G12 & Desplazado & Estancia XVIII \\
\hline 19 & Meta & Tipo A, B, C o D & - & - & Descontx. & - \\
\hline 20 & - & - & - & K16 & Desplazado & Espacio AE \\
\hline 21 & Meta & Tipo A1 & US 1267 & $\mathrm{~J} 12$ & In situ & Estancia V \\
\hline 22 & Catillus & Tipo A1 & US 1267 & $\mathrm{~J} 12$ & In situ & Estancia V \\
\hline 23 & Meta retallada & - & US 1147 & H14 & Desplazado & Estancia XXI (E) \\
\hline 24 & Meta & Tipo A1 & Contexto an & L15 & In situ & Estancia AB \\
\hline 25 & Catillus & Tipo A1 & Contexto an & $\mathrm{L} 15$ & In situ & Estancia AB \\
\hline 26 & Meta & Tipo A & Contexto b & $\mathrm{J} 15-\mathrm{W}$ & In situ & Estancia II (AI) \\
\hline 27 & Catillus & Tipo A & Contexto $\mathrm{b}$ & $\mathrm{J} 15-\mathrm{W}$ & In situ & Estancia II (AI) \\
\hline 28 & Catillus & Tipo F & UC 1380 & $\mathrm{~J} 17$ & Desplazado & $\begin{array}{l}\text { Reutilizado en muro emiral } \\
\text { UC1380 }\end{array}$ \\
\hline 29 & - & - & - & K15 & Desplazado & Espacio AE (calle) \\
\hline 30 & - & - & - & L16 & Desplazado & Reutilizado en muro 54 \\
\hline
\end{tabular}


de enmangue perfora verticalmente el catillus a lo largo de todo su perfil hasta llegar a atravesarlo, tal y como se comprueba claramente en este ejemplar.

Localización/observaciones: Localización original desconocida. Actualmente en el Cerro de la Cruz, cuadrícula E-15, espacio T.

Datación: 300-100 a.C.

\section{Tipo A3}

\section{No CAT. 5/6 (fig. 5)}

Tipo: Catillus y meta correspondientes a un mismo molino.

Dimensiones: Diámetro exterior: $58.9 \mathrm{~cm}$, profundidad del ojo de la meta de $6.16 \mathrm{~cm}$. Diámetro interior: $18.9 \mathrm{~cm}$.

Material: Caliza/travertino.

Estado: Casi 100\%. Bien conservado.

Tipología: Tipo A3, caracterizado por contar con hasta cuatro muescas de enmangue en su perímetro, formando dos parejas perpendiculares entre sí; la primera de las cuales viene tallada en sentido vertical desde la parte superior de la pieza y trazando un recorrido en "L". La segunda, mucho más pequeña, tallada desde la parte inferior y de forma cúbica. Desconocemos paralelos de esta variante particular. El ojo de la meta cuenta con leves muescas laterales paralelas de función desconocida, acaso para afianzar mejor un eje de madera provisto a su vez de escotaduras.

Localización/observaciones: Cuadrícula F14, Estancia $\mathrm{O}$, contexto ' $\mathrm{b}$ '. Molino hallado en el extremo oriental de la estancia ' $\mathrm{O}$ ', junto a la puerta hacia el espacio P. Colocado sobre una plataforma de piedra y adobe provista, asimismo, de un canal para la recogida de la harina.

Datación: Mediados siglo II a.C.

\section{Tipo B1}

\section{No CAT. 7 (fig. 6)}

Tipo: Catillus.

Dimensiones: Diámetro exterior: $29.3 \mathrm{~cm}$, diámetro interior: $6.8 \mathrm{~cm}$.

Material: Granito.

Estado: Buena conservación de ca. 50\% de la pieza.

Tipología: Tipo B1. Superficie superior inclinada al interior. Dotado de sendos mamelones laterales de los que se conserva uno completo con sus dos apéndices. Llamamos la atención sobre el material granítico elegido para la factura de este objeto, ajeno a la geología local. Ello nos permite suponer que nos hallamos ante una evidencia de importación.

Paralelos: Esta pieza la podríamos encuadrar en la tipología R2-A3 de Alonso (1999: 242-243, fig. 153), así como en la tipología B2.3 (variante D1447MRR) de Fernández de Avilés (Berrocal 2006: 289) de volandera cónica/cilíndrica con dos orejetas, documentado en numerosos yacimientos del levante y sur peninsular en el siglo III a.C. (Berrocal 2006: 291). Encontramos modelos muy similares en el Alt del Punxó, Cataluña (Espí et al. 2009: fig. 11) y también alguna semejanza con un ejemplar proveniente del yacimiento ibérico de Taratrato de Alcañiz (pieza D.1600) con dibujo de Fernández de Avilés (Berrocal 2006: 283). Merece señalarse que tanto su material (granito) como la forma 'en $\mathrm{T}$ invertida' de las muescas laterales son extrañas a las producciones ibéricas meridionales y más coherente con las producciones del NE peninsular. Así, conocemos un ejemplo similar, provisto igualmente de orejetas laterales, si bien con muescas en forma de $\mathrm{L}$, no en $\mathrm{T}$ como el caso que aquí se estudia, $\mathrm{y}$ tallado en piedra caliza, no granito como en nuestro caso. Este ejemplar, procedente del cercano yacimiento de Los Zurriones (Priego de Córdoba) se encuentra depositado en el Museo Arqueológico de este mismo municipio (Anderson 2011: 3).

Localización/observaciones: Cuadrícula J15-W, contexto g, bolsa 83. Hallado en la estancia AI. Esta pieza se halló in situ en excavación, pero las reducidas dimensiones del espacio donde se encontraba impedían su rotación, por lo que probablemente estuviera almacenado.

Datación: Mediados del siglo II a.C.

\section{Tipo B2}

\section{$N^{0}$ CAT. 8 (fig. 6)}

Tipo: Catillus

Dimensiones: Diámetro exterior: $29.9 \mathrm{~cm}$, diámetro interior: $6.7 \mathrm{~cm}$.

Material: Caliza/travertino.

Estado: Buena conservación que alcanza a más del $50 \%$ de la pieza original.

Tipología: Pertenece al modelo o tipo B2, modelo que se caracteriza por la presencia de dos mamelones a cada lado, entre los cuales se afianzaba el montante. De estos mamelones se conservan únicamente dos, aunque se intuye la existencia original de otros dos apéndices que harían un total de cuatro (dos por cada lado). Se asemeja al modelo B1, ya discutido 


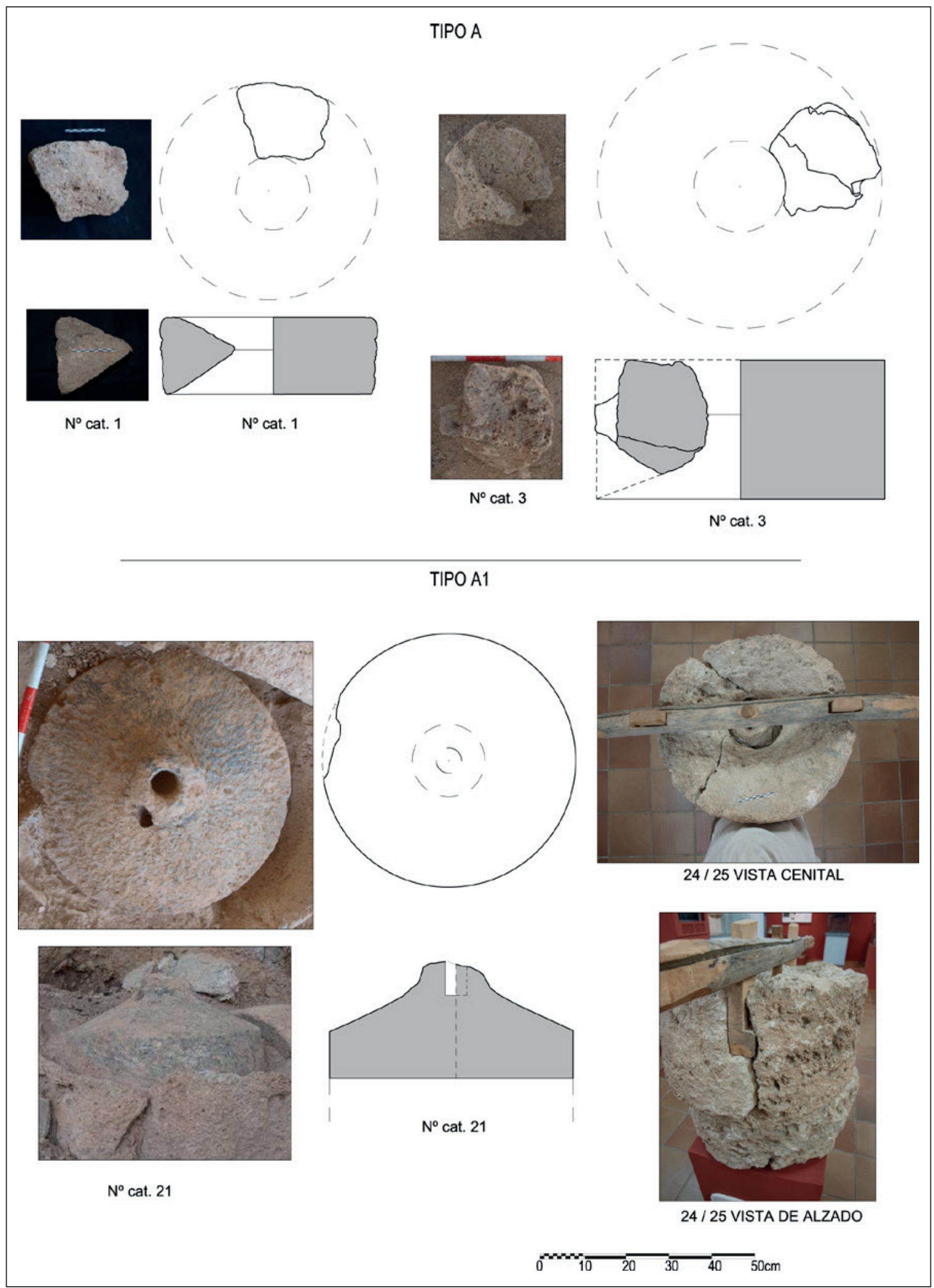

Figura 4. Catálogo de molinos del Cerro de la Cruz (1/6). Tipos A, A1, números de catálogo 1, 3, 21, 24/25.

ISSN: $1133-4525 \quad$ ISSN-e: $2255-3924$

SPAL 23 (2014): 83-118

http://dx.doi.org/10.12795/spal.2014.i23.05 
anteriormente (vid. $\mathrm{n}^{\mathrm{o}}$ cat. 7), pero el caso que aquí tratamos está tallado en piedra caliza (y no granítica como aquél), por lo que podría tratarse de una variante local, y con piedra local, del modelo B1.

Paralelos: Esta pieza guarda cierta semejanza con el tipo B2.2, variante D1396-T de la tipología creada por Fernández de Avilés (Berrocal 2006: 289, fig. 8) pero de la que distingue porque, en nuestro caso, las orejetas se proyectan desde la base del catillus y no desde su cima.

Localización/observaciones: Cuadrícula K13, US 1295. Hallado en la confluencia de los muros ibéricos UC 1317, UC 1213 y UC 1199. El exiguo espacio entre dichos muros permite descartar una ubicación en uso para este molino y podemos suponer que su ubicación respondiera al mero almacenaje o acaso como apoyo o soporte.

Datación: Siglo II a.C.

\section{Tipo C}

\section{No CAT. 9 (fig. 7)}

Tipo: Catillus

Dimensiones: Diámetro exterior: $c a .55 \mathrm{~cm}$, diámetro interior: $15 \mathrm{~cm}$.

Material: Caliza/travertino

Estado: Menos del 25\% conservado. Muy rodado.

Tipología: Pieza fragmentaria y muy rodada, lo que nos impide identificar algún tipo de muesca o enmangue. Pertenece al tipo $\mathrm{C}$.

Paralelos: Desconocemos paralelos correspondientes a esta variante concreta.

Localización/observaciones: Actualmente se encuentra anejo a la valla de límite $\mathrm{W}$ del yacimiento. Sin procedencia.

Datación: 300-100 a.C.

\section{Tipo D}

\section{No CAT. 10 (fig. 7)}

Tipo: Catillus

Dimensiones: Diámetro exterior: ca. $38 \mathrm{~cm}$, diámetro interior: $11.7 \mathrm{~cm}$.

Material: Caliza/travertino

Estado: Menos del 25\% conservado. Muy deteriorado y rodado, a pesar de lo cual se aprecia claramente una muesca lateral para el enmangue.

Tipología: Tipo D. Sólo se conserva una muesca, de las dos que con toda seguridad tendría en origen. Se trata de una muesca vertical destinada a acoger un enmangue igualmente vertical. Este tipo de enmangues exige duplicidad.

Paralelos: Guarda cierta semejanza con el tipo M-1 de los estudiados en el yacimiento de Alorda Park (Asensio et al. 2000-2001: 68), modelo datado en torno al 300-200 a.C. (Asensio et al. 2000-2001: 65). En ambos casos el catillus presenta una parte superior convexa y dos muescas laterales paralelas cercanas a la base y no a la cima, como en la mayoría de los casos. También comparte la muesca lateral cercana a la base con un ejemplar del castro de Nostián (Berrocal 2006: 280, fig. 3) del que, sin embargo, se distingue al carecer este último de superficie convexa.

Localización/observaciones: Descontextualizada.

Datación: 300-100 a.C.

\section{Tipos A, B, C o D}

\section{No CAT. 17 (fig. 8)}

Tipo: Meta.

Dimensiones: Diámetro exterior: $56.1 \mathrm{~cm}$, diámetro interior: $28 \mathrm{~cm}$, profundidad de $11.9 \mathrm{~cm}$.

Área de fricción: $2477.54 \mathrm{~cm}^{2}$.

Material: Caliza/travertino.

Estado: Casi 100\% conservado. Erosión en torno al oído.

Tipología: No se considera tipología para meta. Sin embargo, podría corresponderse con un molino cuyo catillus perteneciera a la tipología $\mathrm{A}, \mathrm{B}, \mathrm{C}, \mathrm{o} \mathrm{D}$, todas ellas de filiación cultural ibérica.

Paralelos: Morfología correspondiente al modelo genérico de metae ibéricas, de desarrollo en el área cultural ibérica desde el siglo V a.C. (Longepierre 2012: 103).

Localización/observaciones: Cuadrícula I12, US 1020. Hallado in situ en la estancia V durante la excavación 2006. Esta pieza podría estar relacionada con el fragmento de catillus $\mathrm{n}^{\circ}$ cat. 2 .

Datación: Mediados del siglo II a.C.

\section{No CAT. 18 (fig. 8)}

Tipo: Catillus.

Dimensiones: Diámetro exterior: $53.4 \mathrm{~cm}$, diámetro interior: $9,8 \mathrm{~cm}$.

Material: Caliza/travertino.

Estado: Menos del 50\%. Muy rodado.

Tipología: Pieza aparentemente inacabada, lo que nos impide identificar su tipología, pero probablemente correspondiente a un molino de tipo A, B, C o D. 


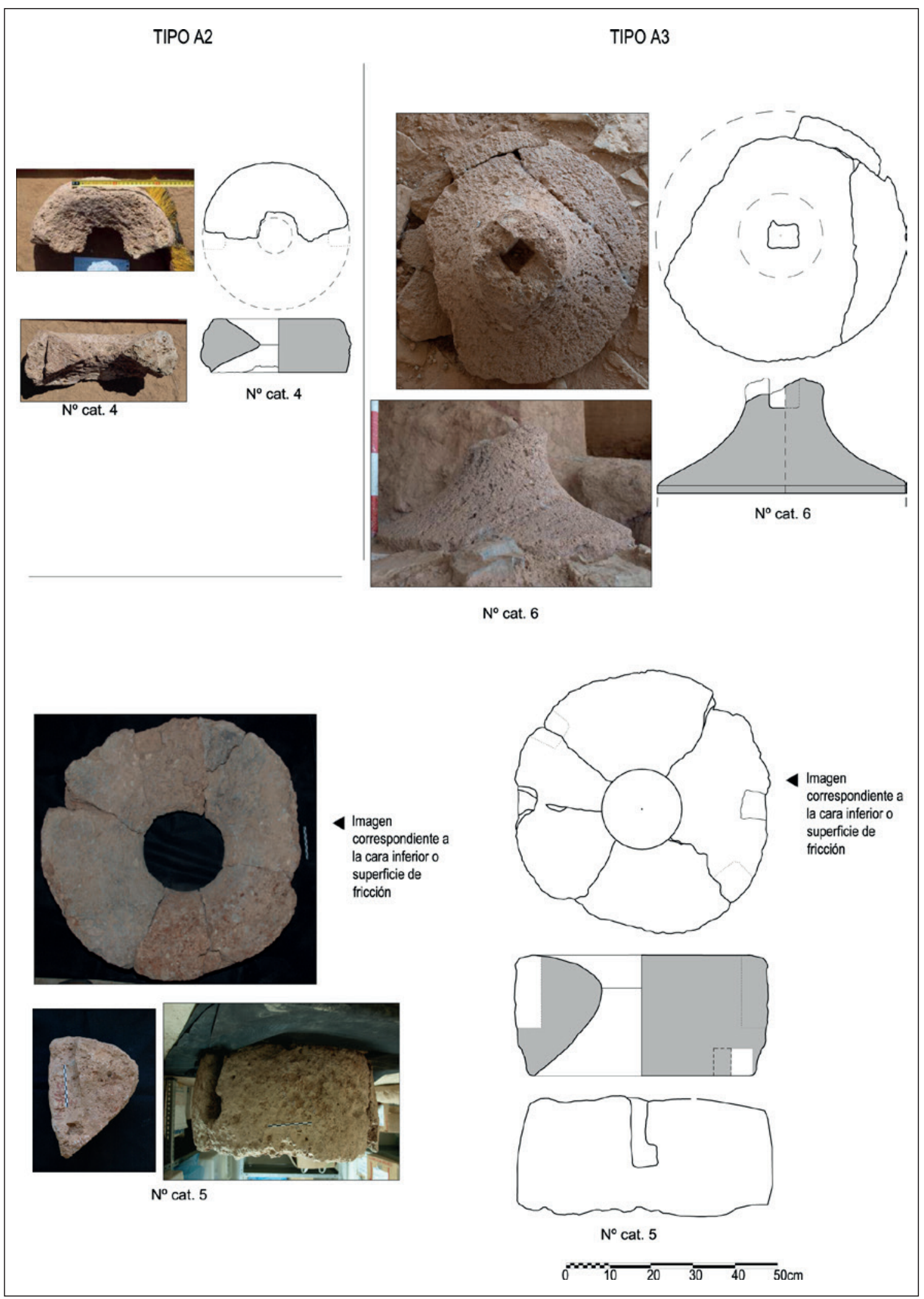

Figura 5. Catálogo de molinos del Cerro de la Cruz (2/6). Tipos A2, A3, nos. cat. 4, 5 y 6. 


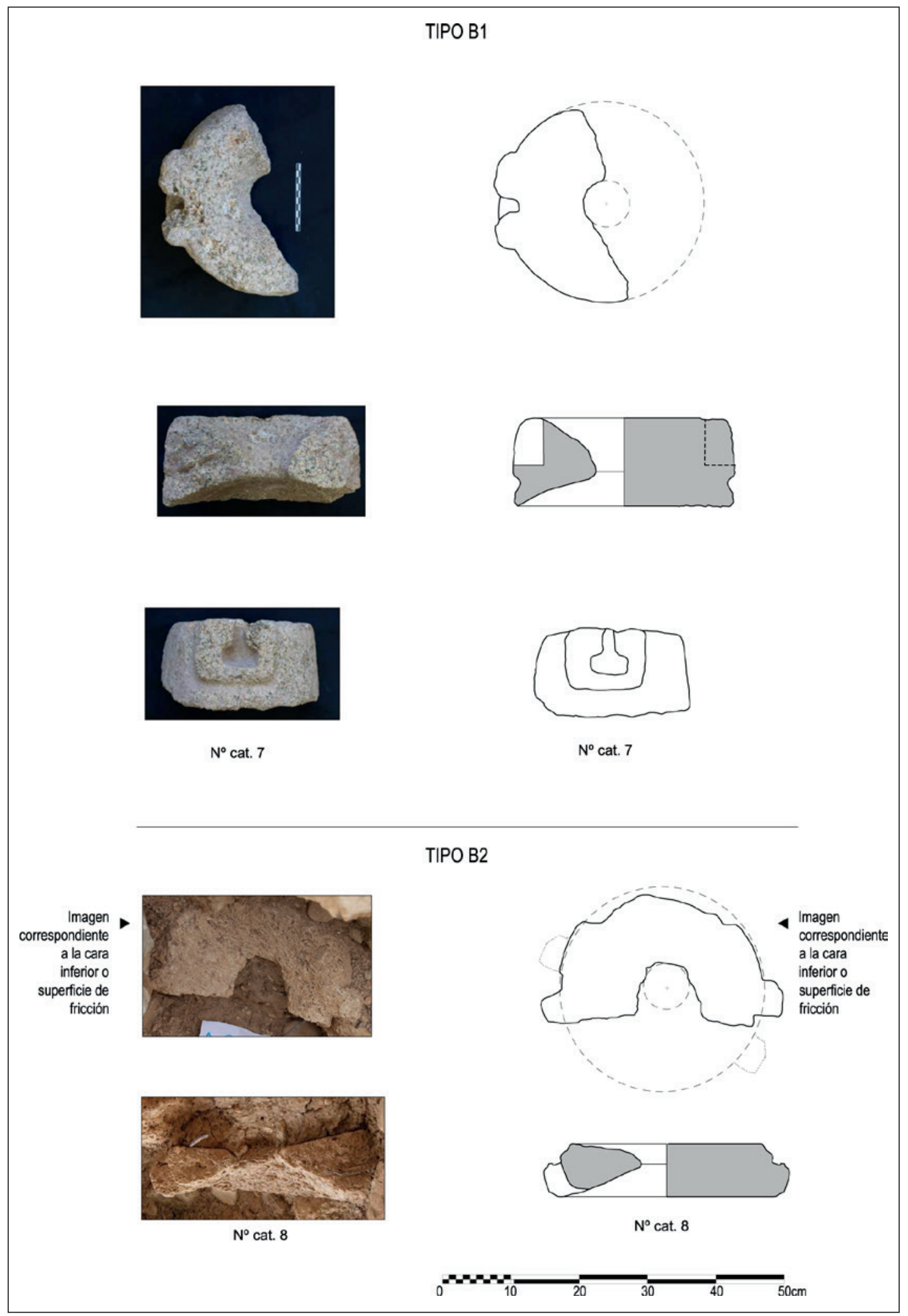

Figura 6. Catálogo de molinos del Cerro de la Cruz (3/6). Tipos B1, B2, nos. cat. 7 y 8. 


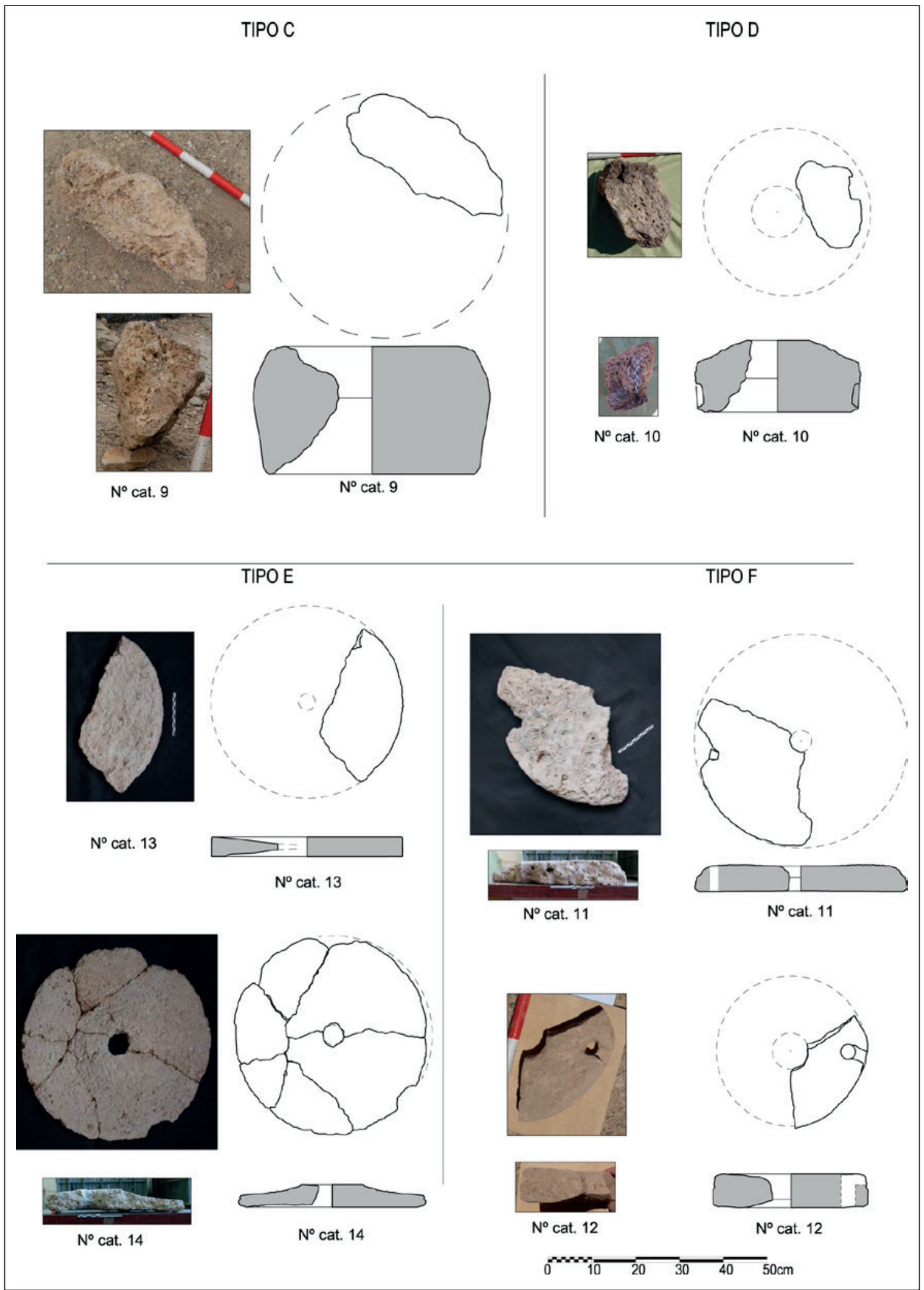

Figura 7. Catálogo de molinos del Cerro de la Cruz (4/6). Tipos C, D, E y F, nos. cat. 9, 10, 11, 1213 y 14.

ISSN: $1133-4525$ ISSN-e: $2255-3924$ 
Localización/observaciones: Cuadrícula G12, US 1161, Estancia XVIII (=I). Desplazado.

La principal característica de esta pieza es que está inacabada, ya que en la superficie de abrasión o de uso presenta una protuberancia que indica claramente que su talla no se ha completado. Podría ser un indicio de la fabricación local de algunos molinos.

Datación: ¿300-100 a.C.?

\section{No CAT. 19 (fig. 8)}

Tipo: Meta.

Dimensiones: Diámetro exterior: $50 \mathrm{~cm}$, área de fricción: $2306.96 \mathrm{~cm}$.

Material: Caliza/travertino.

Estado: Más del 50\%. Incompleta, habiendo perdido el apéndice superior.

Tipología: No se considera tipología para meta, sin embargo podría corresponderse a un molino cuyo catillus perteneciera a la tipología A, B, C o D.

Localización/observaciones: Por una fotografía de los años ochenta sabemos que procede de la zona central, sin más precisiones.

Datación: 300-100 a.C.

\section{No CAT. 23 (fig. 9)}

Tipo: Meta retocada.

Dimensiones: Diámetro exterior: $35 \mathrm{~cm}$, diámetro interior: $3.79 \mathrm{~cm}$ (podría no ser el ojo), con una profundidad de $3.52 \mathrm{~cm}$, área de fricción: $983.28 \mathrm{~cm}^{2}$.

Material: Caliza/travertino.

Estado: Antiguo molino modificado, retallado hasta eliminar su cima y nivelar su superficie.

Tipología: La asignación a un tipo concreto es difícil, por haber sido reconvertido en un objeto distinto que nos impide conocer su aspecto original. No obstante parece corresponderse con una antigua meta de tipo ibérico.

Localización/observaciones: Cuadrícula H14, US 1147. Nivel de suelo del semisótano estancia XXI. Nivel de destrucción e incendio. Quemada por el incendio. Se trata de una meta retocada. La cima ha sido rebajada para dotarla de una superficie plana. Sin embargo, aún en el borde de la cara superior se aprecia un área claramente pulimentada o abrasada por efecto del movimiento del catillus sobre él. El objetivo de la modificación de la pieza nos es desconocido, acaso para una utilización como apoyo o base (pie derecho) de columna o alguna otra estructura, amortizando con ello su función original de molienda. La reutilización de molinos para usos edilicios es una función atestiguada en otros yacimientos, tal y como se constata, por ejemplo, en el yacimiento de Ullastret (Genis 1985:119).

Datación de segundo uso: Mediados del siglo II a.C.

\section{Tipo A o D}

No CAT. 2 (fig. 9)

Tipo: Catillus.

Dimensiones: Diámetro exterior: ca. $38 \mathrm{~cm}$, diámetro interior: $5,5 \mathrm{~cm}$.

Material: Caliza/travertino.

Estado: Menos del 25\%. Muy mal conservado, muy rodado.

Tipología: Indefinida. Podría pertenecer a la familia de los tipos A o D, siendo imposible precisar más. Su estado fragmentario nos impide identificar muescas en su perfil, sin perjuicio de que las poseyera en origen. Paralelos: Sin paralelos conocidos.

Localización/observaciones: Localización original desconocida.

Datación: ¿300-100 a.C.?

\section{Tipo E}

\section{$N^{0}$ CAT. 13/14 (fig. 7)}

Tipo: Catillus y meta de un mismo molino.

Dimensiones: Diámetro exterior: $45.3 \mathrm{~cm}$, diámetro interior: indeterminado, diámetro del oído: $4.5 \mathrm{~cm}$, área de fricción: $1612 \mathrm{~cm}^{2}$.

Material: Caliza/travertino.

Estado: Casi 50\% conservado.

Tipología: Tipo E. La escasa extensión del perímetro conservado del catillus nos impide determinar la existencia y forma de una eventual muesca para enmangue. Muy probablemente se corresponda con la parte activa (meta) $\mathrm{n}^{\mathrm{o}}$ cat. 14 .

Paralelos: Hay suficientes indicios que nos permiten sostener la filiación romana de este ejemplar, como parecen sugerir fuertemente su similitud con las variantes de molino romano I.1 y I.2.a según la clasificación de Gudea (1997: 240-241); así como los modelos igualmente romanos de la tipología B2e de Py (1992: 203-204), datados en este último caso entre los años 150 y 125 a.C., fecha perfectamente coherente con el horizonte ibérico del Cerro de la Cruz. La presencia de un orificio vertical central u ojo que atraviesa completamente la meta es una característica ajena tanto a la tipología ibérica como 


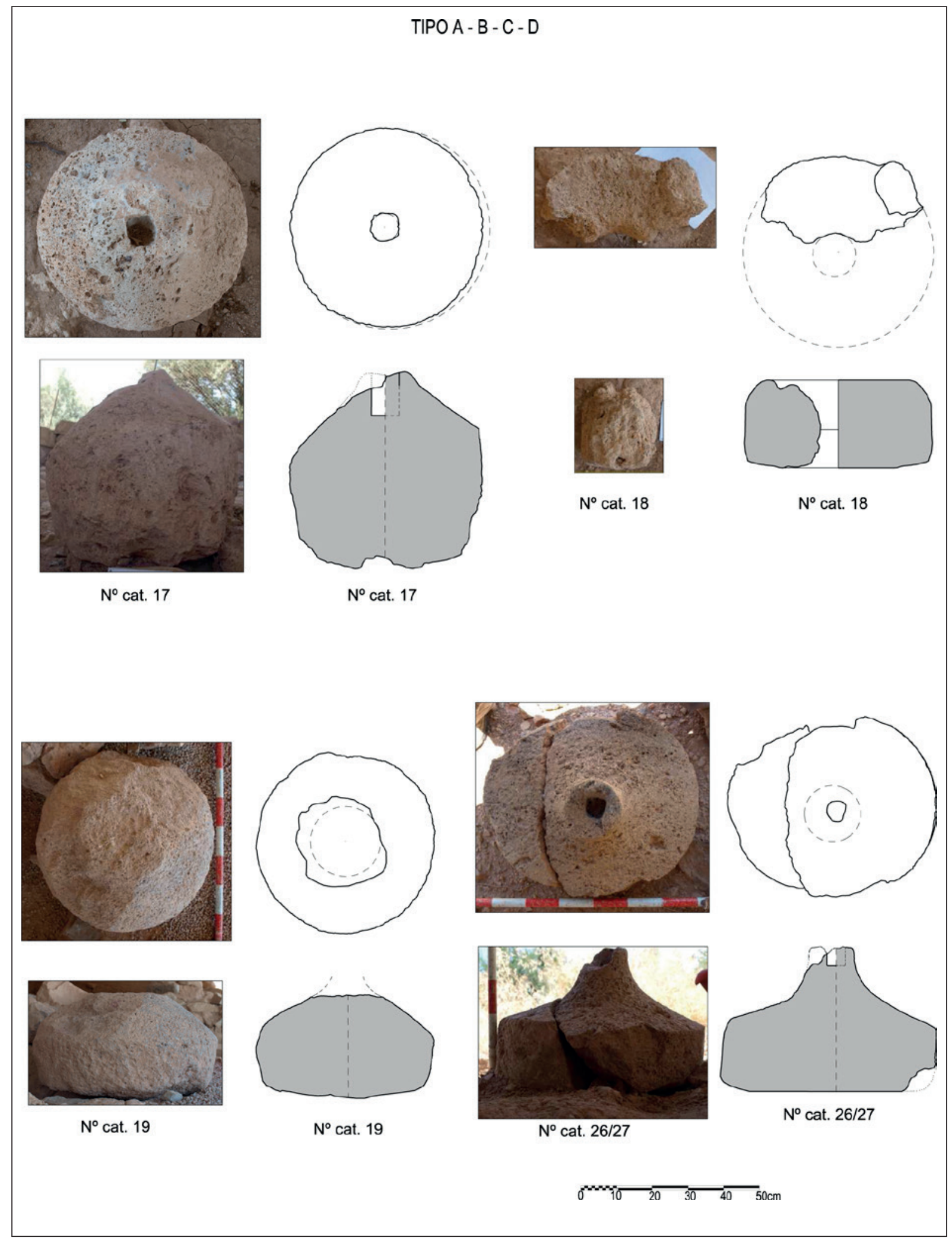

Figura 8. Catálogo de molinos del Cerro de la Cruz (5/6). Tipos A, B, C, D, nos. cat. 17, 18, 19 y 26/27.

ISSN: $1133-4525 \quad$ ISSN-e: $2255-3924$ 
a la medieval, y propia, sin embargo, de la romana. Se trataría, en suma, de un ejemplo de molino de tipología y probable factura romana, importado y utilizado en contexto ibérico.

Localización/observaciones: I14 (desplazado). US 1034 (bolsa 178). Sobre estancia XXII-XXIV.

Datación: Mediados del siglo II a.C.

\section{Tipo F}

\section{No CAT. 11 (fig. 7)}

Tipo: Catillus.

Dimensiones: Diámetro exterior: $48.7 \mathrm{~cm}$, diámetro interior: $4.8 \mathrm{~cm}$.

Material: Caliza/travertino.

Estado: Casi 50\% conservado, y en buen estado. Se observa claramente la superficie de abrasión.

Tipología: Tipo F, superficie de abrasión o fricción completamente plana. Presenta un orificio vertical para enmangue que atraviesa todo el perfil. Ambas características son propias de los modelos de época medieval (vid. infra).

Paralelos: Podemos identificar paralelos similares a este modelo en los yacimientos de El Castillón (Montefrío, Granada), datados entre los siglos VIIIX d.C. (Motos 1991: 190), en Cabezo del Moro, en torno al siglo X (Gutiérrez 1996b: 205-206), Yecla (Burgos) (González 1945: 31) o Vascos (Izquierdo 1979: 365 y lám. XI-2).

Localización/observaciones: Cuadrícula I11, bolsa 081, junto a muro medieval UC 1028 , en la US 1004 con material medieval, superficial, ubicación coherente con la cronología propuesta en función de la tipología.

Datación: 700-1000 d.C.

\section{No CAT. 12 (fig. 7)}

Tipo: Catillus

Dimensiones: Diámetro exterior: $34.2 \mathrm{~cm}$, diámetro interior: $8.2 \mathrm{~cm}$.

Material: Caliza/travertino.

Estado: Menos del 50\% conservado.

Tipología: Tipo F.

Paralelos: Como en el caso anterior (vide supra).

Localización/observaciones: Cuadrícula I12, hallada en la UE 1026, en asociación con materiales de cronología tanto ibérica como medieval. La tipología (F) a la que corresponde esta pieza, sin embargo, nos permite identificarla como medieval.

Datación: 700-1000 d.C.
No CAT. 28 (fig. 20)

Tipo: Catillus

Tipología: Tipo F.

Localización/observaciones: Molino de tipología medieval (tipo F) reutilizado en el zócalo del tosco muro emiral UC 1380. Este hecho nos permite suponer que el periodo de ocupación medieval del yacimiento sea relativamente prolongado, lo suficiente como para permitir la reutilización y amortización de un material tras su rotura accidental.

Datación: ¿700-1000 d.C.?

\section{Sin identificar}

No CAT. 27. Catillus de molino referido en Vaquerizo et al. (1991: fig. 18) y presente en las fotografías de la excavación de 1989 pero actualmente en paradero desconocido.

$\mathbf{N}^{0}$ CAT. 29. Ejemplar referido en Vaquerizo et al. (1991: fig. 18) pero actualmente en paradero desconocido.

$\mathbf{N}^{\mathbf{0}}$ CAT. 30. Ejemplar referido en Vaquerizo et al. (1991: fig. 18) pero actualmente en paradero desconocido.

\section{PLATAFORMAS PARA LOS MOLINOS}

En el yacimiento hemos podido documentar al menos dos, posiblemente tres, estructuras de composición mixta en piedra y adobe, destinadas a la doble función de servir de basamento para los molinos (afianzar el molino en el lugar y evitar que volcase), así como proveer a la labor de molienda de una superficie uniforme donde acumular el producto resultante de la moltura, que en el caso del cereal sería la harina y desde donde éste podría ser fácilmente recogido. Estas estructuras reciben el nombre convencional de "plataformas de molino".

Los ejemplares documentados en nuestro caso proceden de las estancias AB, O y posiblemente XXII, si bien en este último caso su identificación como plataforma es incierta. Su morfología es muy similar, integrando una estructura circular de $c 110 \mathrm{~cm}$ de diámetro y c $25 \mathrm{~cm}$ de altura, compuesta por barro y piedras dispuestas en doble anillo, siendo las piedras del anillo interno de menor tamaño respecto a las del externo. En el centro de la plataforma hallamos la meta del molino embutida hasta la altura de su superficie de fricción con la muela superior (figs. 10 y 11). Sobre la plataforma y 


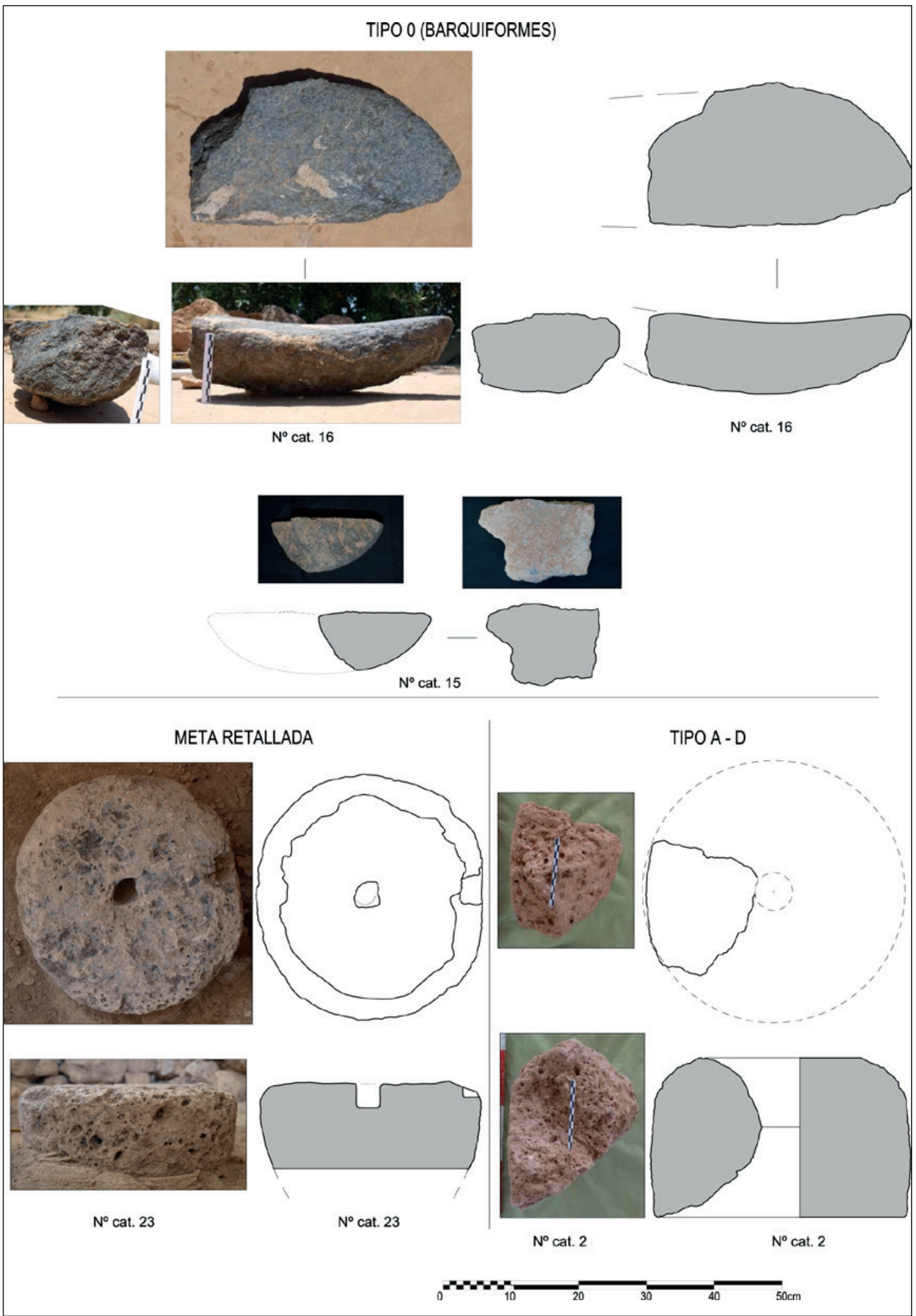

Figura 9. Catálogo de molinos del Cerro de la Cruz (6/6). Tipo 0, meta retallada y A-D, nos. cat. 2, 15, 16, 23

ISSN: 1133-4525 ISSN-e: 2255-3924 


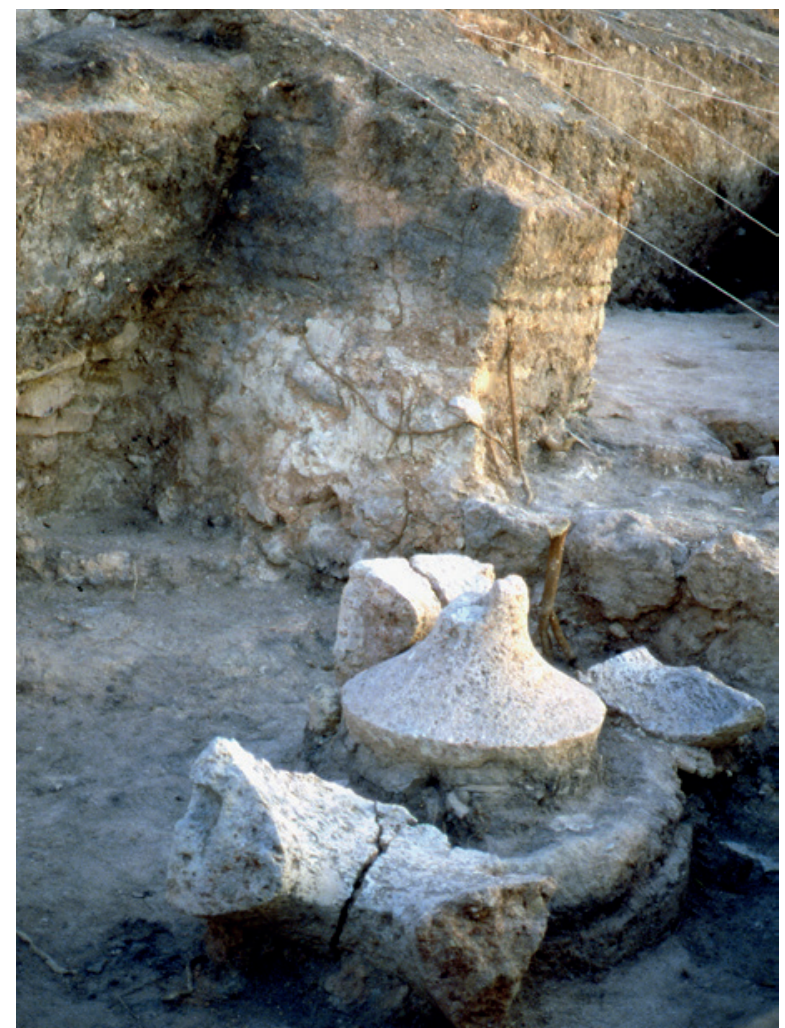

Figura 10. Molino de la estancia "O" (F-14) (n” cat. 6), con la meta in situ sobre una plataforma de adobe con canal perimetral donde se encontró grano y harina carbonizadas y algún plato colocado para recoger la harina que cayera en el proceso de molienda. Campaña de 1987 (ver también Vaquerizo et al. 2001: fig. 48b). en el momento de su excavación se pudo apreciar, en el caso de la estancia $\mathrm{O}$, un enlucido de adobe provisto de un canal para la recepción de la harina (Vaquerizo et al. 2001: 131-132).

El uso de este tipo de plataformas bajas no es desde luego exclusivo de este yacimiento, hallándose en numerosos yacimientos ibéricos de época plena como el Alt del Punxó:

La zona central de la estancia [...], está ocupada por una estructura de planta circular realizada en mampostería de piedras irregulares con un diámetro de $80 \mathrm{~cm}$ y del que solo se conserva una hilada de alzado. Esta estructura presenta unas características similares al poyo localizado en la estancia 1 , de lo que se deduce que pudo tener una función similar de soporte de un molino. Esta interpretación se fundamenta en la localización de diversos fragmentos de las muelas superior e inferior de un nuevo molino rotatorio, similar al de la estancia 1, entre los niveles de derrumbe de esta estructura (Espí Pérez 2009: 38).

En Torre la Sal, en Cabanes (ss. III-I a.C.) aparecen también estructuras similares (Flors 2009: 192).

Lo mismo ocurre en el poblado de El Tossal de Sant Miquel de Liria, a fines del s. III a.C., en cuyo Departamento 42a aparece una plataforma circular de $1 \mathrm{~m}$ de diámetro y $0,28 \mathrm{~m}$ de altura, considerada una gran área de trabajo, debido a la presencia de molino para cereal (Bonet 1995: 179). Más importante aún, en el Dpto. 46 del mismo asentamiento apareció otro gran molino circular en lo que se ha considerado un área de
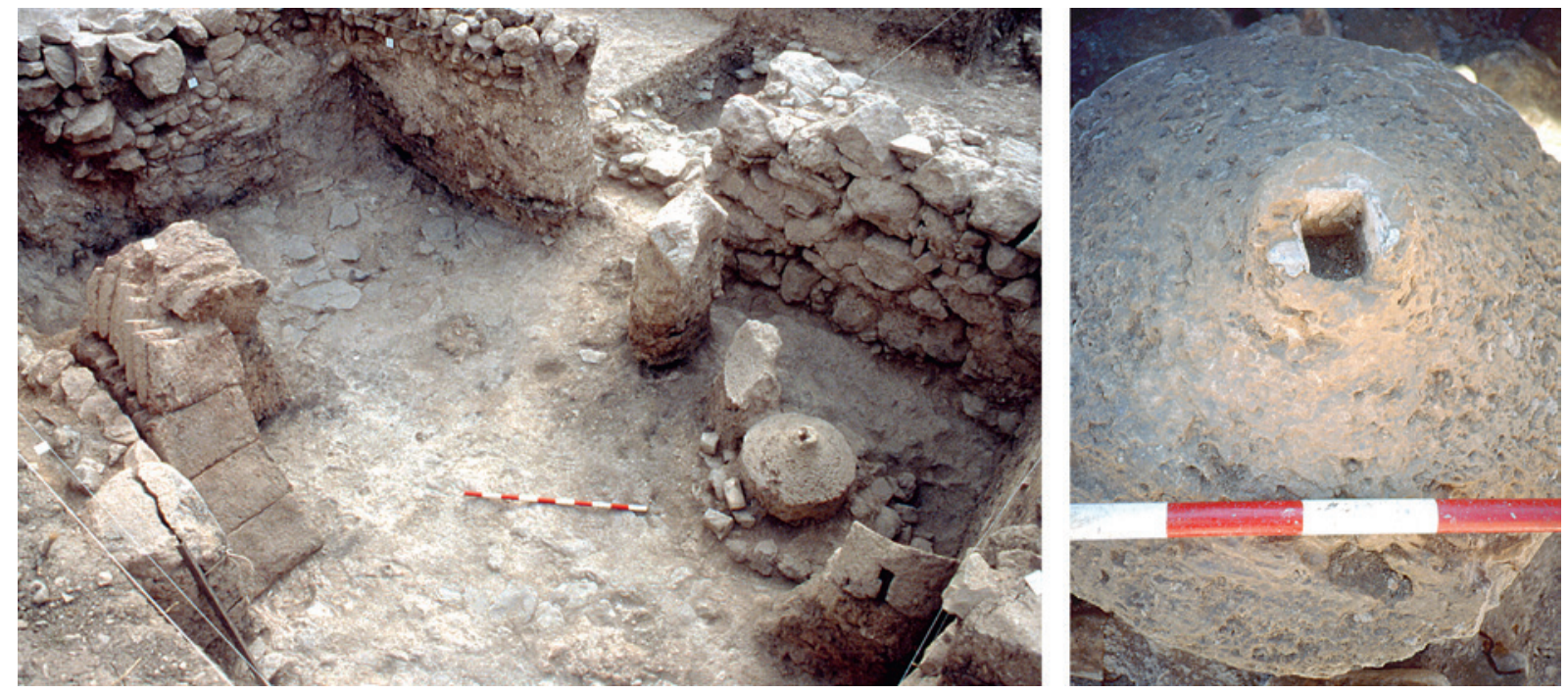

Figura 11. Patio en la zona norte de la excavación, estancia AB, con puerta para carros y molino in situ en la esquina suroeste del espacio (nº 24/25). El orificio de la meta para el eje está forrado de lámina de plomo, para asegurar la sujeción de la pieza de madera embutida en él. 


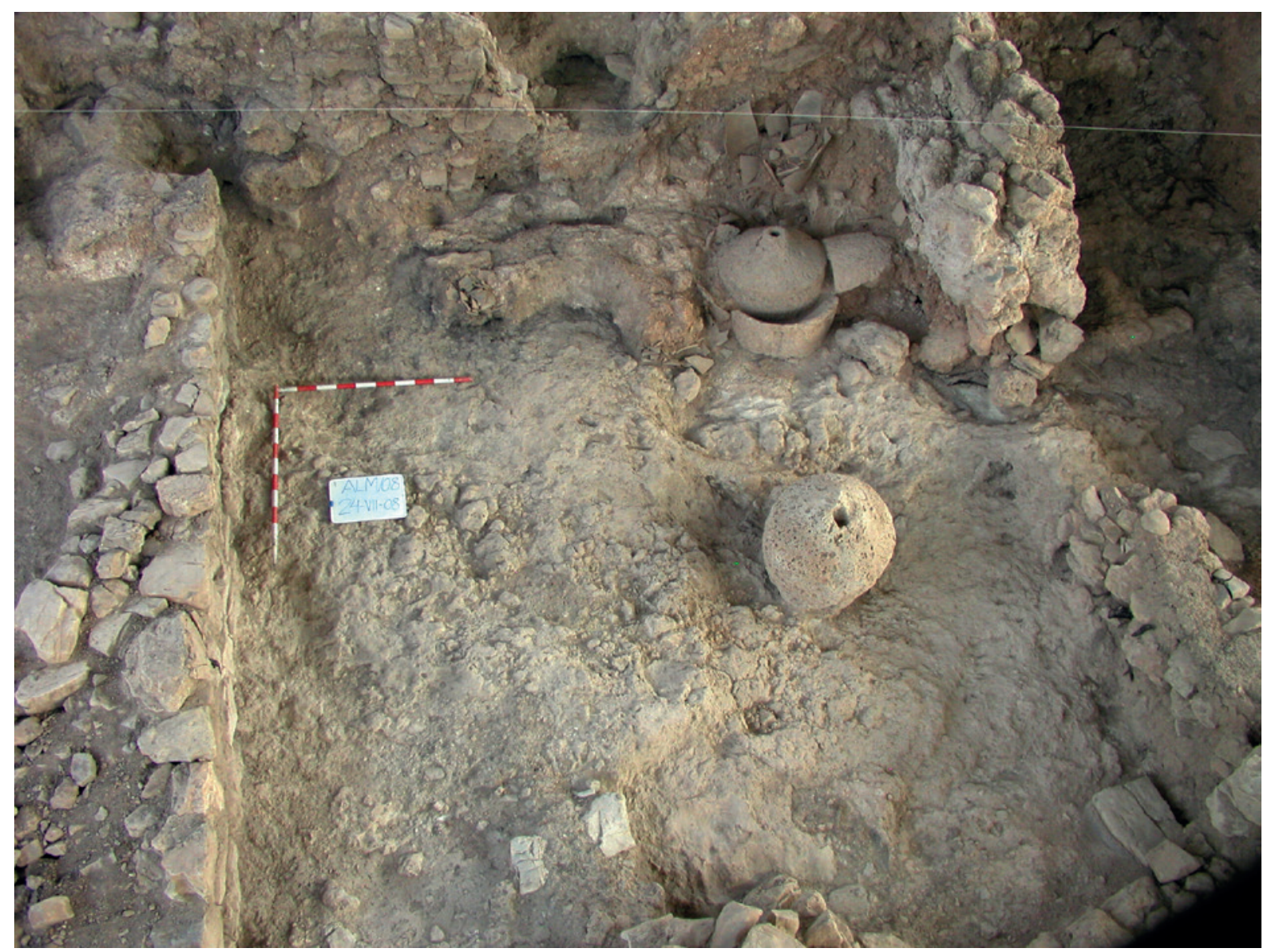

Figura 12. Molinos del espacio abierto V (nos. cat. 21/22 al norte, parte superior; $n^{\circ}$. cat. 17 en el centro). El primero de ellos estaba encajonado entre ánforas y fuera de uso en el momento de la destrucción del poblado.

molienda de carácter comunitario (vid. infra) (Bonet 1995: 356, fig. 187). En el Departamento 4 del Puntal dels Llops (Olocau, Valencia) se documenta un molino asentado sobre un podio o basamento cilíndrico, pero aquí de $85 \mathrm{~cm}$ de altura, realizado en piedra y adobe y revestido de un enlucido de arcilla blanquecina, dejando una acanaladura que servía para recoger el cereal molido como en el Cerro de la Cruz (Bonet y Mata 2002: 57). Este caso es muy diferente al del Cerro de la Cruz: una plataforma de casi $1 \mathrm{~m}$ de altura implica un molino 'de sangre', accionado por personas en posición erguida o por animales.

La plataforma circular sobre el suelo no es sin embargo universal; en otros poblados ibéricos, como en Tossal del Moro de Pinyeres, un molino rotatorio asociado a uno de vaivén aparece sobre un alto rebanco a su vez adosado a un muro (Arteaga et al. 1990: 61 ss. y fig. 9).

Sea como fuere, en el Cerro de la Cruz la posición y altura de las plataformas conservadas es consistente no con una posición en pie sino con un trabajo en posición acuclillada, arrodillada o sentada. El diámetro de los molinos (en la mayoría de los casos en torno a los $50 \mathrm{~cm}$, fig. 17), es consistente con esta postura (también Alonso 2000:134).

\section{CONTEXTO Y DISCUSIÓN: LOS MOLINOS DE ÉPOCA IBÉRICA}

La mayoría de los molinos se documentan en contextos de estancia y dentro de los mismos es usual localizar las metae o partes pasivas in situ que, al ser piezas pesadas y poco manejables, dificultan su traslado y resisten bien los procesos postdeposicionales. No sucede igual con los catilli, que por su mayor fragilidad y menor volumen tienden a aparecer fragmentados y en lugares ajenos a su contexto original. En algunos yacimientos, como Alorda Park, la ausencia de molinos 
rotativos in situ en el interior de las casas puede ser atribuida a un abandono progresivo del lugar (Asensio et al. 2000-2001: 58). En el caso del Cerro de la Cruz el fenómeno es inverso, un repentino abandono tras un incendio y destrucción violenta asociado a un episodio bélico que impidió a sus ocupantes el rescate de los bienes muebles (Quesada et al. 2010: 92ss.). Se ha propuesto en algún caso que el menor peso de las partes activas (catilli) respecto a las pasivas (metae), habría favorecido la desaparición de los catilli del yacimiento dejando solo las metae (Guérin 1999: 90). En esta misma línea, en el yacimiento de Molí de Espigol, los investigadores son bastante cautelosos a la hora de interpretar los espacios de molienda al haber documentado solamente una piedra de molino aislado, ya que estas piezas podrían haber sido transportables (Camañes 2010b: 185).

Contamos como se ha dicho con fragmentos de molinos naviformes, uno de los cuales ( $\mathrm{n}^{\circ}$ cat. 15) fue hallado en contexto probablemente ibérico (estancia XVIII), aunque aparentemente desplazado. Nos resulta particularmente interesante la constatación de estos testimonios pues son la prueba de la coexistencia de molinos rotatorios y naviformes o de vaivén en el siglo II a.C. Los naviformes no deben ser necesariamente entendidos como un rasgo de primitivismo pues, según han señalado otros autores, podrían ser más idóneos para la molienda de cereales vestidos como la cebada, en contraposición con los desnudos como el trigo común (Alonso 2000: 134). Tampoco podemos descartar su uso en la molienda de otros materiales distintos a los alimentos, como pigmentos o minerales o para usos diferentes como pulir o afilar objetos de hueso.

Los ejemplares rotatorios hallados completos, esto es, con ambas piezas (pasiva y activa) presentes y en su lugar de reposo original (in situ), son por lógica aquellos susceptibles de suministrar un mayor volumen de información (figs. 10, 11, 12 y 15).

Contamos con hasta seis ejemplos que podrían entrar en este grupo; ahora bien, de entre ellos debemos distinguir dos subcategorías. En primer lugar, aquellos a los que el fin del poblado ibérico sorprendió en su lugar de uso - de molienda-; y en segundo lugar aquellos otros que probablemente estaban en reserva, almacenados (fig. 12). Hemos de atender al hecho de que la presencia de un molino en una estancia no implica necesariamente su uso en esa misma estancia.

Sin embargo, el hecho de haber documentado una piedra de molino aislada no nos permite hablar con total seguridad de un espacio de molienda, ya que este tipo de elementos podrían haber sido transportables y, por lo tanto, su presencia no confirma su utilidad in situ (Alonso 1999). Por esta razón, este dato se debe tomar con cierta precaución y muestra la necesidad de considerarlos conjuntamente con el resto de elementos que constituyen el ámbito donde son testimoniados. Los sectores en los que fueron localizadas, en su mayoría, no mostraban un uso especializado sino que, por el contrario, demarcaban áreas plurifuncionales, constatándose a su vez actividades de tejido o/y almacenaje (Camañes 2010b: 185).

Los molinos, aunque pesados, podrían haberse trasladado de una estancia a otra según las necesidades. El transporte de estos objetos no habría de ser necesariamente muy difícil. En el caso de los molinos de grandes dimensiones (tipos A, B, C, D), hemos de entender que su muela superior o catillus estaría embrazada por una viga horizontal de madera, lo que facilitaría su traslado.

La distinción entre molinos en posición 'de trabajo' y otros 'almacenados' no es inmediatamente evidente y representa uno de los mayores problemas que suscita su interpretación. Los indicios que nos permiten suponer una ubicación laboral de un molino son, en primer lugar, la presencia de una plataforma bajo la meta, prueba evidente de que efectivamente aquel sería el lugar donde se operaría. En segundo lugar, los molinos rotatorios requieren un cierto espacio en derredor que permita el giro del eje horizontal (viga o palanca) del mismo, así como de las personas o animales que impulsan el mecanismo, por lo que aquellos molinos confinados en espacios muy reducidos (en ocasiones menos de $15 \mathrm{~cm}$ respecto a paredes o grupos de recipientes cerámicos de gran tamaño) no podrían haber sido accionados. Por último, la separación muy acusada entre las dos piezas componentes de todo molino rotatorio sugiere igualmente su almacenaje, aunque no es determinante pues la separación de ambas piezas puede en algún caso haber sido accidental, producto del colapso de las estructuras edilicias sobre los molinos.

Atendiendo a estos criterios entendemos, por tanto, que con seguridad estaban en uso, incluso literalmente usándose, en el momento de la destrucción del poblado los molinos nos. cat. 24/25, 5/6 y, acaso también el 17. Los dos primeros se apoyaban sobre las plataformas de molino ya mencionadas (vid. supra). Por lo mismo, es evidente que al menos estos dos ejemplares estaban en uso en el momento del fin del poblado ibérico (figs. 10, 11).

Contamos también con un posible indicio de una tercera plataforma de molino hallada en la estancia XXII. Sin embargo, todo apunta a que se halla en un estrato de época emiral y sin presencia de molino sobre ésta, lo que nos impide identificarla claramente como tal. 


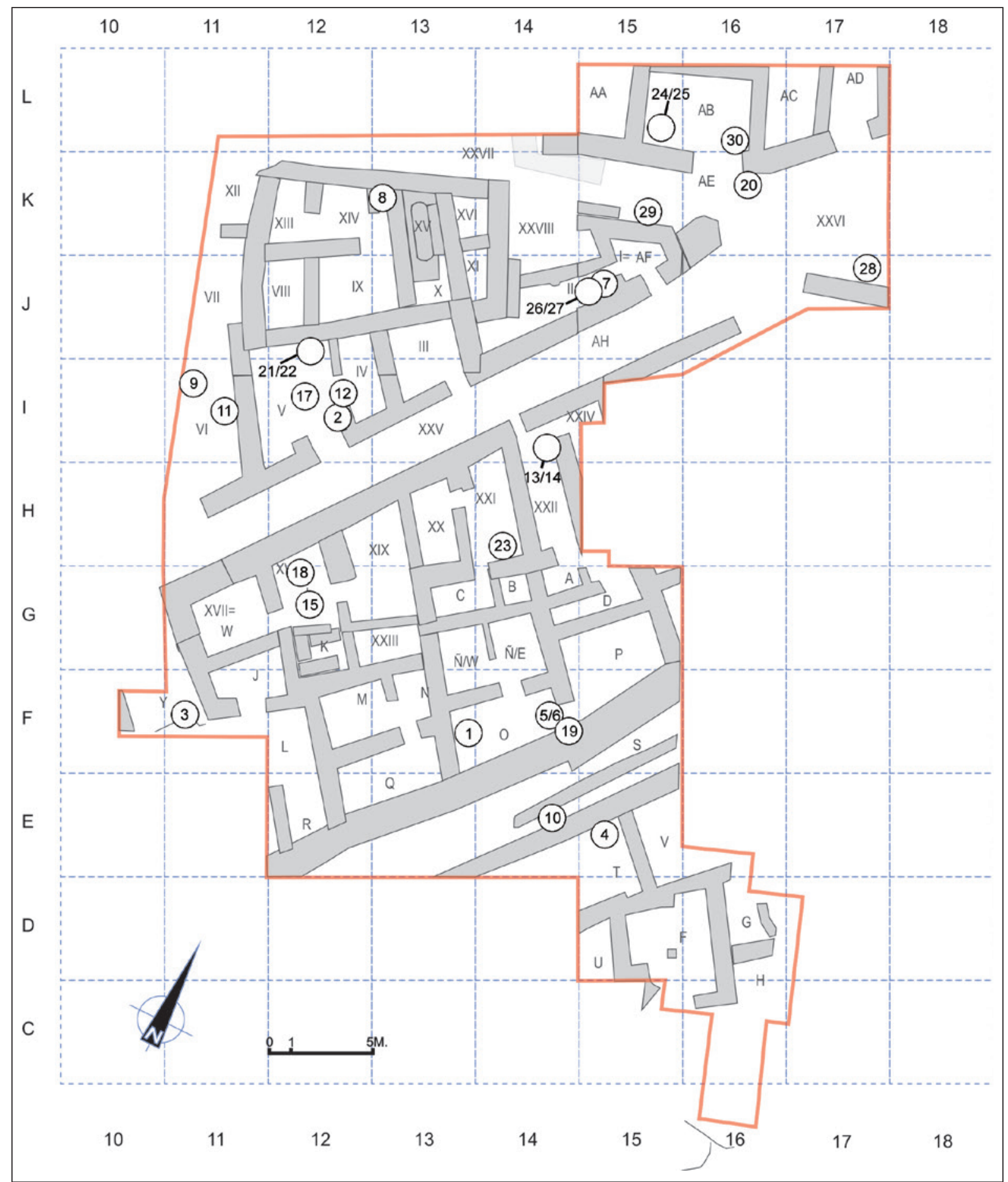

Figura 13. Plano de la zona central excavada del yacimiento con indicación mediante número de catálogo de los molinos hallados (incluyendo los medievales), indicando el número de catálogo y la denominación de los espacios del poblado ibérico. 
En la misma estancia XXII (fig. 13), pero en nivel de uso ibérico, se halló un molino completo ( $\left.{ }^{\circ} 13 / 14\right)$, hallado en la UE 1034, junto al muro UC 1057, cuya tipología parece corresponderse con un modelo romano republicano del tercer cuarto del siglo II a.C. (supra tipo "E"), por tanto plenamente coincidente con la fecha propuesta para el poblado ibérico. El lugar de hallazgo es un pasillo relativamente estrecho (vid. fig. 15) pero dado que se trata de un molino de reducidas dimensiones, es probable que fuera activado por una única persona, sin necesidad de que ésta girara en torno al molino. Ello permite el uso de este molino en lugares estrechos y en cercanía con la pared.

En cuanto al molino $\mathrm{n}^{\mathrm{o}} 17$, apareció en el centro de la estancia $\mathrm{V}$ y con suficiente espacio en derredor para el movimiento de los obreros -o animales- que lo impulsaran, por lo que podría haber estado en uso. La ausencia de plataforma y pieza activa asociadas nos impide afirmarlo con rotundidad, toda vez que cabría su desplazamiento en el momento del colapso de las paredes circundantes, desde una posición ligeramente al norte, junto al molino 21/22.

Por el contrario, algunos de los molinos parecen haber estado almacenados y no en uso, como se deduce del lugar en el que fueron hallados. Algunos aparecen en estancias diminutas y abarrotadas de otros objetos, especialmente ánforas prácticamente adosadas a los mismos, tal como sucede con los molinos 7 y 26/27. Casi con seguridad, este fuera también el caso del molino rotatorio $21 / 22$, hallado completo (piezas pasiva y activa) pero en una proximidad tal con dos de los muros de la estancia (muros UC1237 y UC1344 de la estancia V) y emparedado entre una hilera de cuatro tinajas ibéricas, justo al norte, y un ánfora grecoitálica, justo al sur, que hace imposible su uso efectivo. Incluso asumiendo un giro parcial y no completo de la muela superior, la cercanía tan estrecha con el paramento habría impedido la recogida de la harina vertida.

En estos casos debemos suponer que los molinos estaban en reserva, almacenados, y en espera de ser sacados de la estancia para ser utilizados. En apoyo de esta hipótesis está el hecho de que en ocasiones hallamos piezas activa y pasiva separadas, lo que redunda en la impresión de almacenaje.

Por fin, contamos con una serie de ejemplares cuya ubicación resulta difícil explicar en términos de empleo. Así, contamos con varios fragmentos de un mismo catillus en el fondo del aljibe ibérico de la estancia "O" (núm. cat. 1). En este caso, parecería en apariencia razonable suponer que fue arrojado intencionadamente como pieza de desecho una vez amortizado el aljibe.
Pero el contexto arqueológico de destrucción violenta es claro. La pieza perteneció al nivel de uso de la estancia, donde el aljibe de la habitación $\mathrm{O}$ estaba cubierto por planchas de madera, al contrario que su vecino de la estancia Q, tapado con grandes lajas de piedra. En el momento del incendio y derrumbe, el catillus, que quizá procediera incluso de una planta superior, acabó en medio de los escombros y maderos que rellenaron bruscamente el aljibe (ver al respecto sobre el hundimiento del aljibe también Vaquerizo 1990:102-103).

A estos casos debemos añadir una serie de fragmentos desplazados, hallados en ubicación distinta a su lugar de origen. Así, documentamos fragmentos de molino sobre los espacios de calle o plaza ibéricos XXVI, XXVII e "Y" (n ${ }^{\text {os }}$ cat. 29, 31 y 3) que podrían ser bien ser productos de desecho, bien piezas reutilizadas para la construcción de la propia calle o, por último, molinos que sencillamente estuvieran depositados o cuyo uso se obrara en la propia calle, a la sombra de los aleros de las casas.

Por otro lado, no hemos hallado indicio claro de la colocación de molinos en los pisos superiores o azoteas de las viviendas ibéricas, lo que ciertamente cabría suponer en al menos un espacio (estancia II, cat. 26-27). La potencia de los muros de las construcciones del Cerro de la Cruz, capaces de sostener incluso varios pisos, hace que no descartemos de antemano esta posibilidad, plausible por ejemplo en el caso de la estancia II. De hecho, se ha propuesto esta ubicación en alto en lugares como el Dpto. 4 del Puntal dels LLops (Bonet y Mata 2002: 119) en Valencia o en la terraza del edificio de la Mata de Campanario (Badajoz), yacimiento en el que el $82 \%$ de los molinos -eso sí, de vaivén- procede del piso superior y/o terraza (Rodríguez 2004: 275, figs. 111-112), aunque todo ello en fechas más antiguas que las del Cerro de la Cruz.

La impresión que proporcionan todos estos datos es que no había un modelo de estancia específica para el trabajo de la molienda. Así, encontramos molinos en uso en estancias delanteras de las plantas bajas de las casas, quizá en forma de porche (estancia “O”), pero sobre todo en patios (estancias V, AB), y en estancias que son casi corredores anchos (XXII). Los fragmentos hallados en las calles podrían sugerir el uso de estos instrumentos en ese medio, aunque no son en absoluto prueba de ello, pues pueden haber sido desplazados desde otro lugar, acaso en el momento de la destrucción del poblado o en las alteraciones estratigráficas que sabemos experimentó el yacimiento en época medieval.

Merece comentario también un ejemplar ( $\mathrm{n}^{\circ}$ cat. 7$)$, cuya tipología infrecuente (tipo B) y material (granito) 


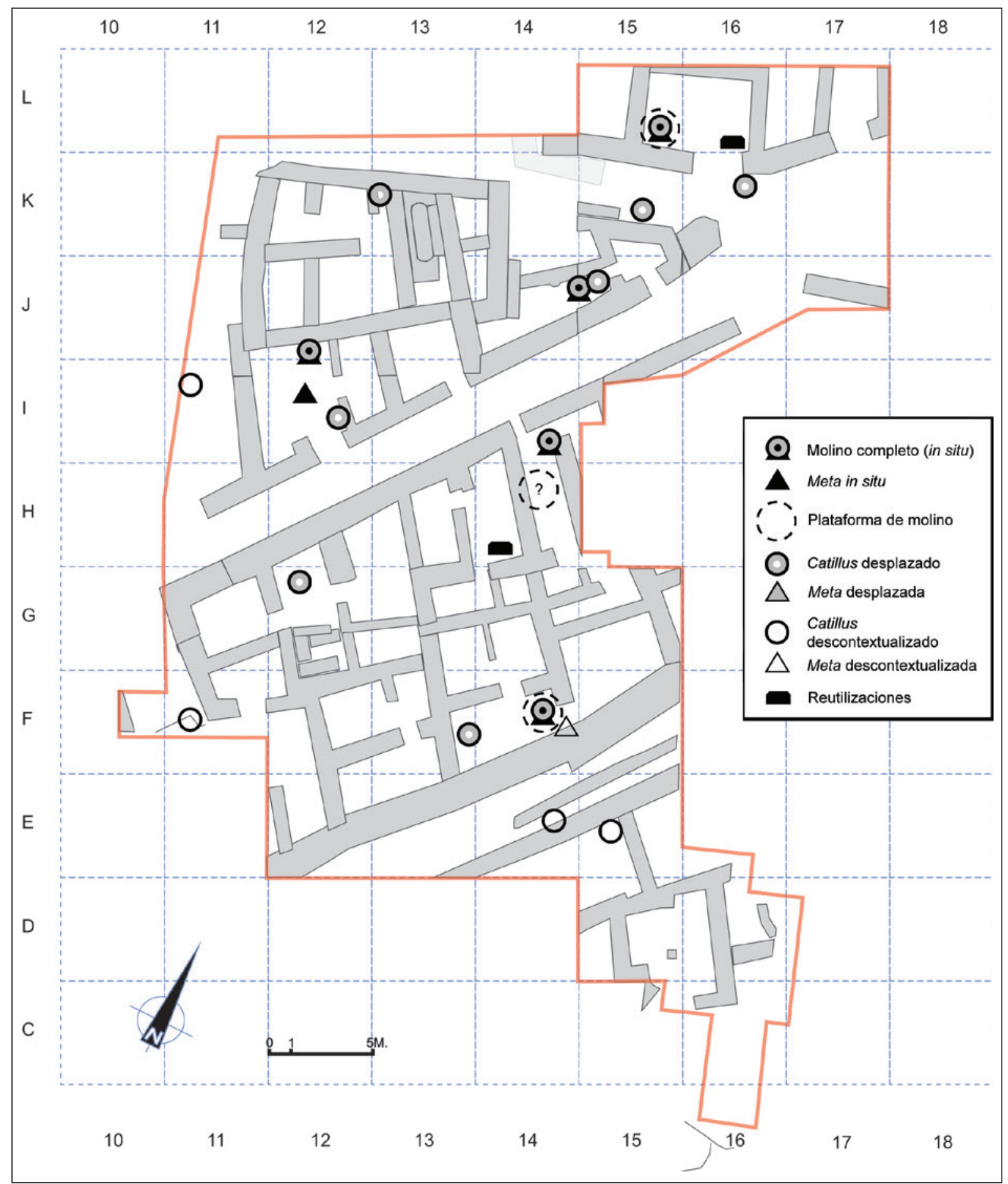

Figura 14. Plano de la fase ibérica del yacimiento con indicación de los molinos hallados, indicando su carácter, en cada caso. 


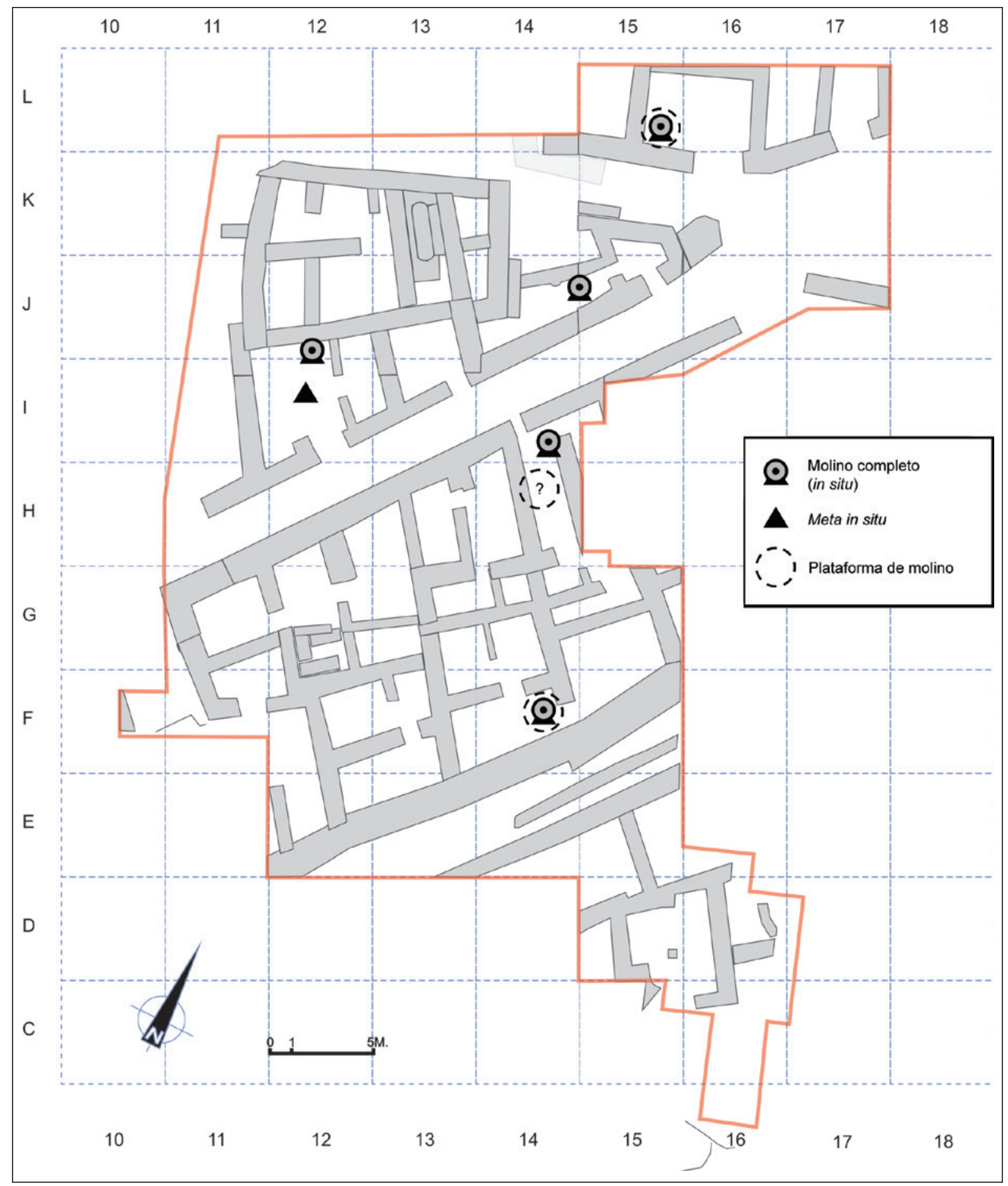

Figura 15. Plano de la fase ibérica del yacimiento con indicación de los molinos hallados in situ. 


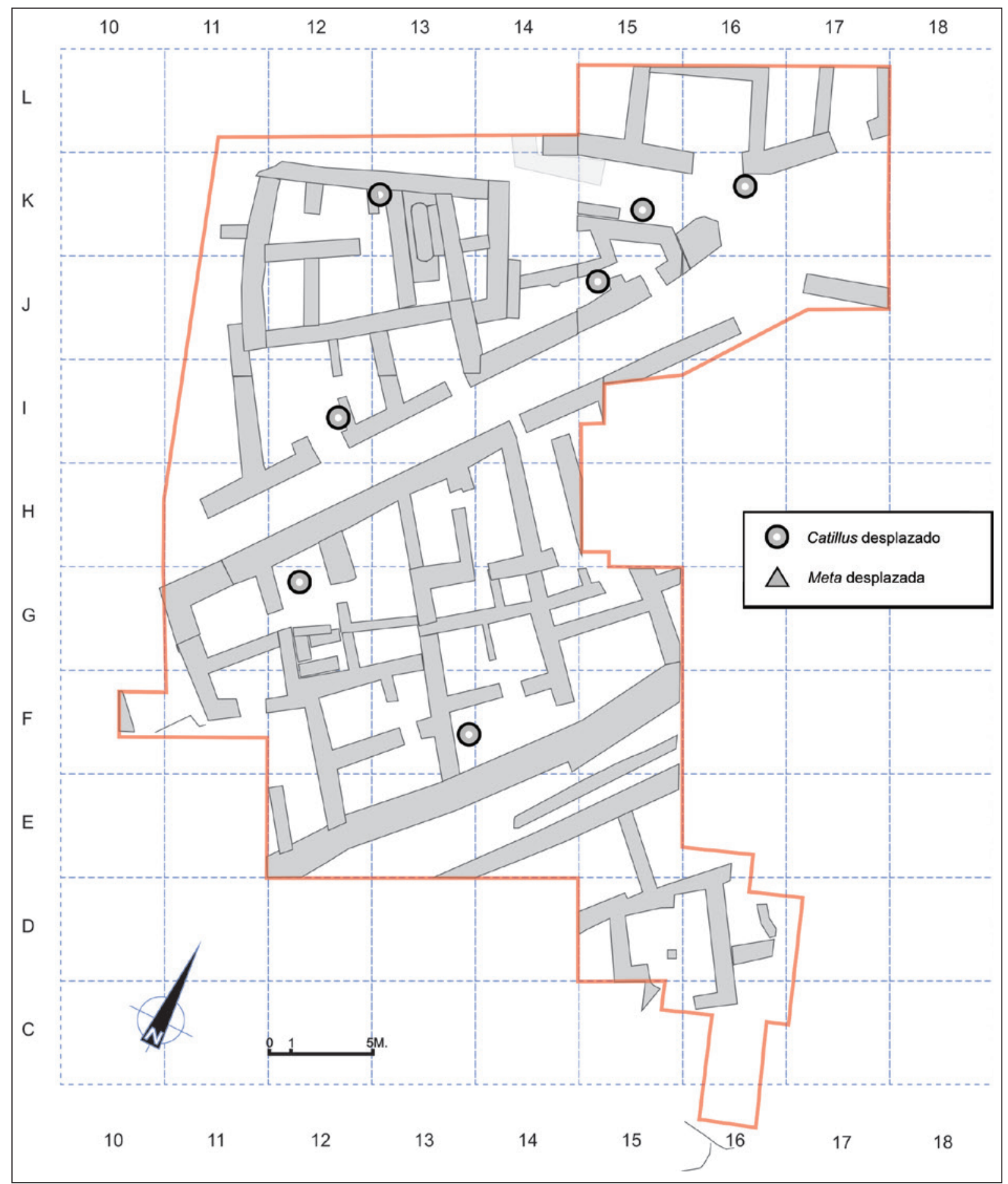

Figura 16. Plano de la fase ibérica del Cerro de la Cruz con indicación de los molinos hallados desplazados, esto es, en posición distinta a la ocupada mientras permanecieron en uso. 
se corresponden plenamente con modelos propios del NE peninsular (Alonso 1999: 254, Alonso 2000: 135, Asensio 2000-01: 69, Espí 2009: fig. 11, Sanmartí 1992: fig. 37), siendo por el contrario ajenos a los yacimientos meridionales. Asimismo, el área en torno al Cerro de la Cruz carece de canteras de piedra granítica, lo que hace más que probable que nos hallemos ante un objeto importado desde regiones quizá alejadas (sería excesivo proponer el NE peninsular), con las implicaciones que de ello se deban deducir en cuanto al comercio de piezas de molino en el mundo ibérico.

Un comentario particular merece el caso de aquellos molinos o piezas de molino que han sido reutilizados, quizá una vez dañados, para funciones distintas al diseño original. Este es el caso de la pieza número 23, aparentemente utilizada como pie derecho. Se trata de una pieza pasiva (meta) encajada en el suelo de la habitación y cuya parte superior ha sido tallada (rebajada) para con ello crear una superficie horizontal donde reposar acaso una columna u otro objeto; además, en su centro aún se observa parte del orificio central destinado a acoger el eje del molino. Observamos sin embargo que este retallado no ha afectado al conjunto de la pieza, restando un breve espacio en torno al borde superior, donde todavía se puede apreciar parte de la antigua superficie de fricción, demostrando con ello su muy distinto origen. Se halló en el extremo sur de la estancia XXI (un sótano o semisótano), a escasos 30 $\mathrm{cm}$ de la pared meridional, espacio sin embargo demasiado corto para argumentar una utilidad real como soporte de un pie derecho destinado a sostener un techo de amplia luz.

La reutilización de molinos para usos edilicios es una función también atestiguada en otros yacimientos; así encontramos en Ullastret el empleo de un molino de vaivén para consolidar la pared de una estancia cuando éste dejaba de estar en uso (Genis 1985: 119).

Contamos en el capítulo de las reutilizaciones (aparte de los reaprovechamientos en época medieval) con un fragmento de catillus ibérico de tipo B2 (número 8) que se encontró apoyado sobre el suelo, en la esquina interior entre los muros UC 1317 y UC 1199. Apareció en posición estrictamente horizontal y cubriendo todo el espacio de la esquina, lo que induciría a pensar que fue colocado así a propósito, acaso como base para apoyar ánforas.

La posición del molino $n^{\circ} 5 / 6$ requiere un comentario especial. Se ubica en el espacio (“O”) pero justo en el acceso a la estancia aneja de almacenamiento "P", verdaderamente ‘justo en medio' (fig. 10). Podemos suponer que entre las tres paredes próximas, de gran potencia, sujetaran una segunda planta (documentada además por mechinales en muros de adobe en estancias adyacentes), se erigiera un techo para un segundo piso que cubriría el lugar ocupado por el molino. Frente al conjunto se desarrollaría la calle ("S") de carácter público, utilizada también como vertedero de huesos cocinados. Todo ello parece indicar que el molino se ubica en un espacio privado y probablemente a resguardo de la lluvia y otras inclemencias, pero con una estrecha proximidad y a la vista del espacio público, sin una neta distinción entre lo público y lo privado, detalles quizá no baladíes a la hora de hacer una interpretación social del fenómeno.

Este mismo hecho se documenta también en otros yacimientos ibéricos de periodos similares, tales como el Cerro del Villar, Sa Caleta o La Bastida de les Alcuses, tal y como han puesto de relieve sus respectivos investigadores:

La disposición de algunos molinos en asentamientos como Cerro del Villar o Sa Caleta indica que estos procesos de trabajo no siempre tenían lugar en el interior de las casas, en un ámbito estrictamente privado, sino que en algunos contextos se realizaban en áreas externas a las casas o en espacios abiertos usados de forma comunal por varias unidades domésticas. Este patrón espacial rompe la tradicional dicotomía público/privado y pone en cuestión la idea de que los procesos de preparación de alimentos siempre tienen lugar en ámbitos cerrados y aislados, sin interacción ni visibilidad social. Por el contrario, la distribución de algunas instalaciones e instrumentos usados en la preparación de alimentos en las colonias fenicias occidentales indica que algunos de sus grupos domésticos realizaba parte de estas tareas en espacios comunales y que estos lugares eran importantes escenarios de relación e interacción social (Delgado Hervás, 2010: 36).

[...] en las casas de los conjuntos 3, 4, 5 y 12 no hay molinos, lo que sugiere que ciertos grupos muelen el grano en instalaciones comunitarias, como la identificada en el dept. 155 junto al almacén del conjunto 7 . En conclusión, estos datos permiten defender, en primer lugar, que existen diferencias en las tecnologías culinarias empleadas entre unas casas y otras, y, en segundo, que algunas unidades domésticas deben acceder a estructuras comunitarias de transformación (Iborra et al., 2010: 109).

La ubicación de los molinos parece sugerir que o bien algunos molinos tenían un carácter público, o que las esferas de lo privado y lo público no estaban tan 


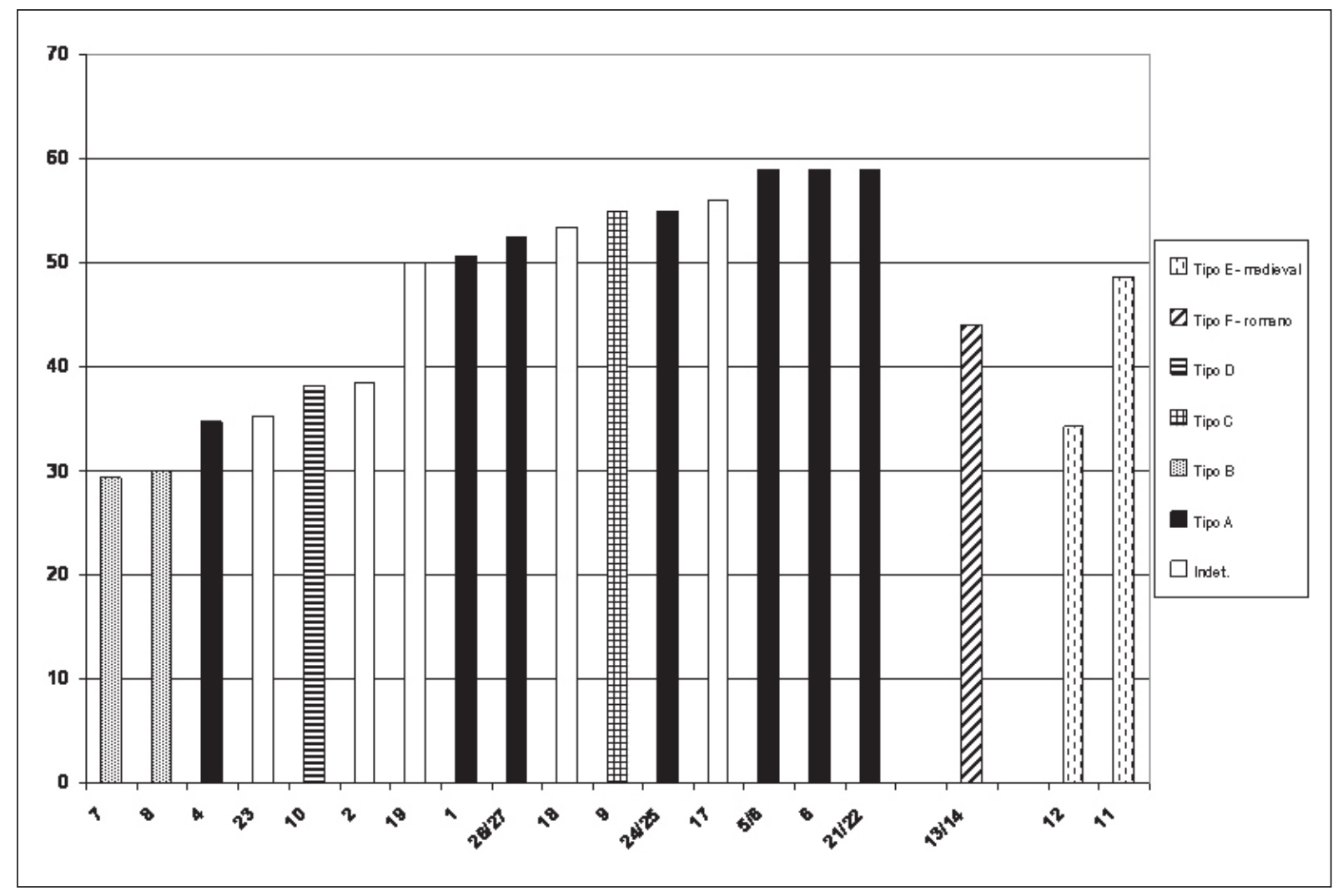

Figura 17. Diámetros de los molinos del Cerro de la Cruz.

netamente diferenciadas como lo querríamos ver hoy, siendo acaso los molinos propiedad o posesión de grupos amplios de población, más allá de la familia nuclear.

Algunos investigadores han propuesto para el mundo ibérico la existencia de molinos y espacios de molienda 'comunitarios' por oposición a privados, y que responderían a un patrón de economía dirigida por autoridades de carácter supra-familiar. El gran tamaño de algunos de estos molinos rotatorios y su concentración en algunos espacios es un argumento a favor de esta hipótesis (Pérez et al. 2000:162 ss.; vid. también Espí y Pérez 2009: 39-40; 46-47). En el caso del Cerro de la Cruz, ciertamente la presencia de grandes molinos, ocasionalmente duplicados en un mismo espacio (estancias II y V) podría sugerir algo similar, sobre todo si complementamos esta información con la existencia de verdaderos almacenes con decenas y hasta más de cuarenta ánforas llenas de grano (fig. 18) o líquido, abiertas a los espacios públicos, cuya capacidad desborda ampliamente el consumo familiar.

Ciertamente llama la atención la ausencia de hogares bien definidos en el área hasta ahora excavada del yacimiento, lo que nos ha llevado a considerar la posibilidad de una especialización laboral en la que las labores de cocina se llevaran a cabo, bien en las plantas altas y/o azoteas que con seguridad existían (Vaquerizo et al. 2001:109), bien en otra zona distinta del poblado, separándose físicamente por tanto de la zona de molienda y otras actividades económicas a gran escala (ibd. p.104). Sin embargo es preciso recordar, en primer lugar, que la ubicua presencia de cenizas en el yacimiento, producto de su destrucción, puede haber camuflado los testimonios; en segundo lugar, la ausencia de hogares identificados como tales quizá no sea prueba suficiente de la ausencia de labores de cocina; y, por último, conocemos de la existencia de un brasero y un trébede, ambos de hierro (hallados en las estancias XVIII y XX respectivamente), que parecen sugerir labores de preparación de alimentos. En el caso del brasero, su posición original fue muy probablemente en un segundo o tercer piso de altura del edificio, como se deduce de la alta cota del derrumbe en que fue hallado; en el caso del trébede por el contrario estaría originalmente a pie de suelo.

Pero sobre todo debemos recordar la conspicua evidencia de otras actividades, fundamentalmente textiles, 


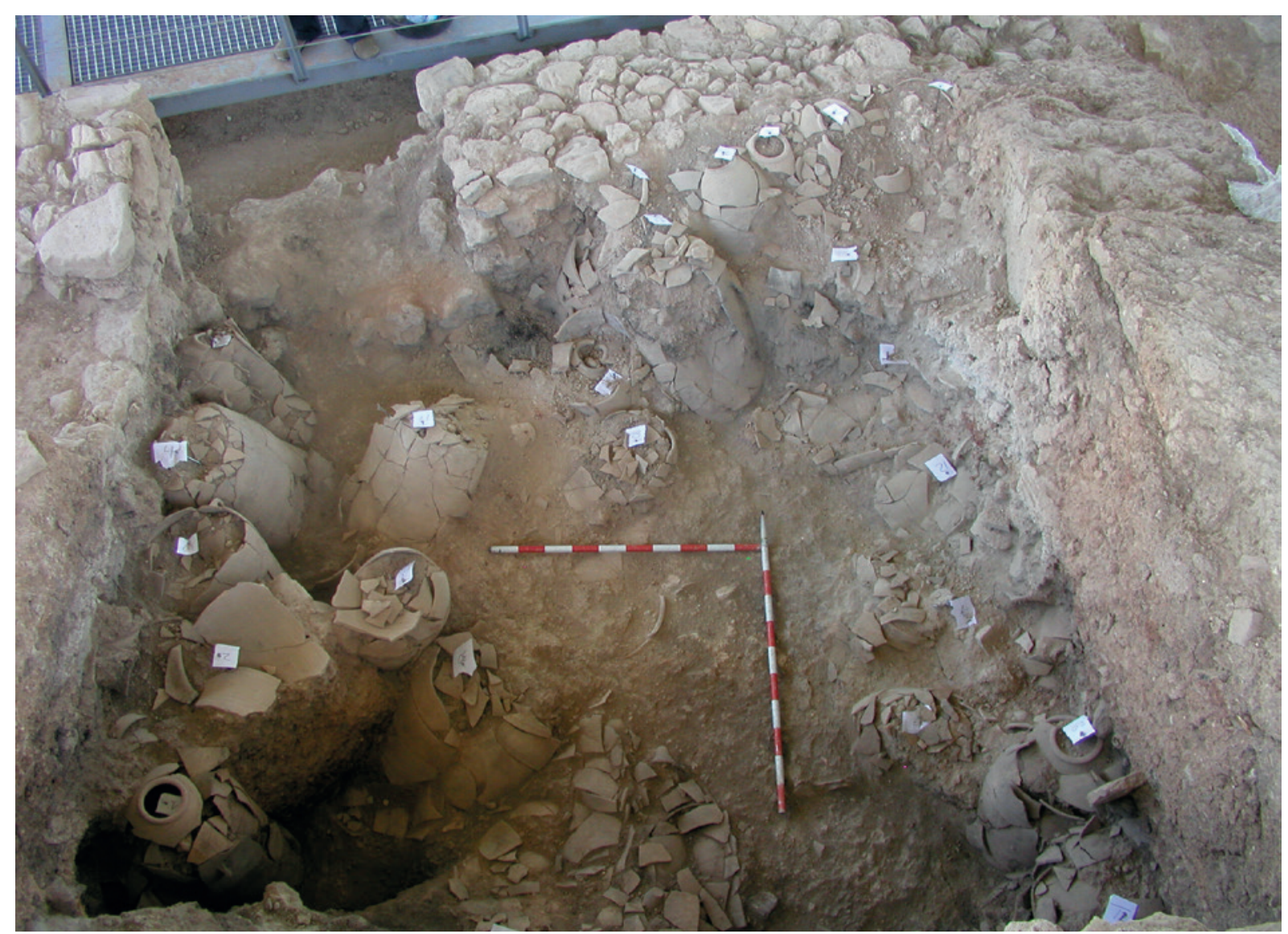

Figura 18. Estancia III, con más de cuarenta tinajas para almacenar grano, abierta exclusivamente a la calle XXV, y aneja a dos zonas con molinos harineros.

en los mismos espacios o adyacentes a donde aparecen los molinos (e.g. Vaquerizo et al. 1991 passim). El gran número de molinos, aljibes, almacenes de ánforas y pesas de telar en la zona excavada del yacimiento nos ha permitido en efecto proponer la hipótesis de que nos hallemos ante una posible zona industrial del poblado ibérico tardío, aunque en todo caso no acotada a un único producto, sino a procesos industriales en sentido lato:

La localización de hasta siete molinos en un espacio menor de 600 metros cuadrados indica una considerable actividad de molienda y lo que resulta en principio más extraño, si nos encontramos ante un área especializada en la transformación de alimentos, es que los molinos se asocien a telares (o al menos a almacenes de pesas de telar) y ocasionalmente a grandes depósitos contiguos de agua. Si hay una especialización zonal, esta es en cualquier caso limitada a una actividad general de transformación/producción, sin una mayor precisión (Vaquerizo, Quesada y Murillo 1991: 183).
Hoy la densidad de molinos ha aumentado.

La dispersión de molinos del Cerro de la Cruz nos ofrece un dato que creemos relevante, como es el hecho de que no comparten el mismo espacio que el grano, ocupando cada uno estancias distintas en el poblado, nunca coincidentes pero sí adyacentes (e.g. espacios V/ III; O/P, etc.). Por otro lado y como hemos apuntado, el volumen de la mayoría de los almacenes de grano, caso particular de la estancia III (fig. 18) pero también los de las estancias I(=AFD), J, P, etc.), literalmente abarrotados de grandes recipientes, sugiere un control del grano, aceite y vino bien comunal o más probablemente organizada y dirigida por grandes familias.

En cuanto al objeto de estas labores de molienda, contamos por ahora con el estudio de A.M. Arnanz (2000) sobre los macrorrestos vegetales carbonizados hallados en la "estancia O" y en el canal de recogida del molino $\mathrm{n}^{\mathrm{o}}$ 5/6, de esta misma estancia (fig. 10). En ambos casos se documentó una gran proporción de semillas de veza (Vicia stativa) y particularmente de yero 
(Vicia ervilia), ambas leguminosas. Concretamente en el canal del mencionado molino las recogidas correspondieron en un $87 \%$ a yero y en un $12 \%$ a veza, documentándose también muy exiguos restos de trigo, cebada y una única semilla de vid. De ello quizá debamos deducir que el molino 5/6 habría sido usado en días o semanas anteriores para la molienda de trigo y cebada (la presencia de la única semilla de vid puede ser accidental), pero que en el preciso momento de la destrucción del poblado se dedicaba a la molienda de yero y veza. O, alternativamente, que las semillas distintas a yero y veza fueran también intrusiones accidentales producto de la imperfecta selección de las semillas.

No podemos saber si estas leguminosas fueron destinadas a consumo humano o animal; se trata de alimentos hoy considerados poco aptos para el consumo humano y, por lo mismo, tradicionalmente empleados para alimentar al ganado, aunque su consumo humano también se documenta ocasionalmente (Arnanz 2000: 241ss). Sin embargo, en algunos de los almacenes del yacimiento (estancia III, por ejemplo) se documentan grandes cantidades de cereal, que parece haber estado en almacenamiento/consumo simultáneamente. Ante esta evidencia caben tres interpretaciones:

a) Que las mencionadas leguminosas fueran destinadas al consumo humano, en el supuesto de una estructura social muy poco igualitaria donde se diera una diferencia en la dieta (cereales o leguminosas) entre unos y otros miembros de la misma comunidad en función de la condición económica o social. Según esta hipótesis, el gran almacén de cereal de la estancia III tendría carácter privado o exclusivo a un sector social.

b) La segunda posibilidad, ya adelantada, es entender que estas leguminosas iban destinadas al consumo animal, hipótesis compatible tanto con una economía de carácter privado como comunitario.

c) La tercera es, simplemente, que en años de barbecho se cultivara yero que se combinaría para la alimentación humana, y quizás también animal, con los cereales de otros años. Esta última opción, lógica además desde el punto de vista de la eficiencia de los cultivos (Arnanz 2000: 242) nos parece más probable.

En todo caso, la existencia del gran depósito de cereal en la estancia III (fig. 18) nos permite desestimar la hipótesis de que el recurso a las mencionadas leguminosas se debiera a una carestía generalizada y, por lo mismo, tal acumulación de grano hace improbable que la destrucción final del poblado ibérico, que como sabemos fue violenta, sorpresiva y vinculada a un episodio bélico, sucediera a un asedio prolongado (Quesada et al. 2013).

\section{LOS MOLINOS DE ÉPOCA ANDALUSÍ EMIRAL}

Incluimos en este trabajo los escasos ejemplares documentados de molinos de época andalusí y periodo emiral en el Cerro de la Cruz porque creemos relevante un estudio integral de los molinos del yacimiento, incluso si los dos conjuntos de materiales están separados entre sí por un hiato correspondiente al periodo romano, y porque además algunos molinos de época andalusí, de forma plana, pueden ser confundidos en museos y colecciones, donde aparecen descontextualizados, con otros de época romana, lo que hace relevante la publicación específica.

Hasta ahora hemos documentado tres casos de molinos de época andalusí en el Cerro de la Cruz. Se trata de modelos que cuentan con una cronología muy amplia, entre los siglos VII-XI (Gutiérrez 1996a: 237). Su tamaño es relativamente pequeño, sin duda como consecuencia del carácter familiar y no comunitario de las industrias alimenticias del periodo (Gutiérrez 1996a: 207) y la propia naturaleza modesta, casi de emergencia, del asentamiento en el Cerro de la Cruz (Carmona 2010, González 2010).

Los ejemplos (fig. 13, números de catálogo 11, 12 y 28) son bastante homogéneos (figs. 9 y 19). Se trata de elementos de catillus casi plano que cuentan con orificio vertical que perfora la pieza, destinado a acoger el enmangue. En uno de los casos ( $n^{\circ}$ cat. 12) la muesca presenta la característica forma de " $\mathrm{L}$ " invertida. Podemos identificar paralelos a este modelo en yacimientos como El Castillón de Montefrío (Granada), ejemplos datados entre los siglos VIII-X d.C. (Motos 1991: 190), en el Cabezo del Moro (Abanilla, Alicante), en torno al siglo X (Gutiérrez 1996b: 205-206) en Yecla (Burgos) (González 1945: 31) o en el conjunto de Vascos (Toledo) (Izquierdo 1979: 365 y Lám. XI-2).

El molino $\mathrm{n}^{0} 11$ procede del sedimento de la US 1004, unidad muy superficial con material medieval y junto al muro medieval UC 1028. Por su parte, el molino $\mathrm{n}^{\mathrm{o}} 12$ se halló en la unidad US 1026, unidad removida muy cercana a la superficie, con una intrusión o fosa medieval. Está realizado en piedra arenisca, material ajeno a los molinos de época ibérica o romana en la zona. 


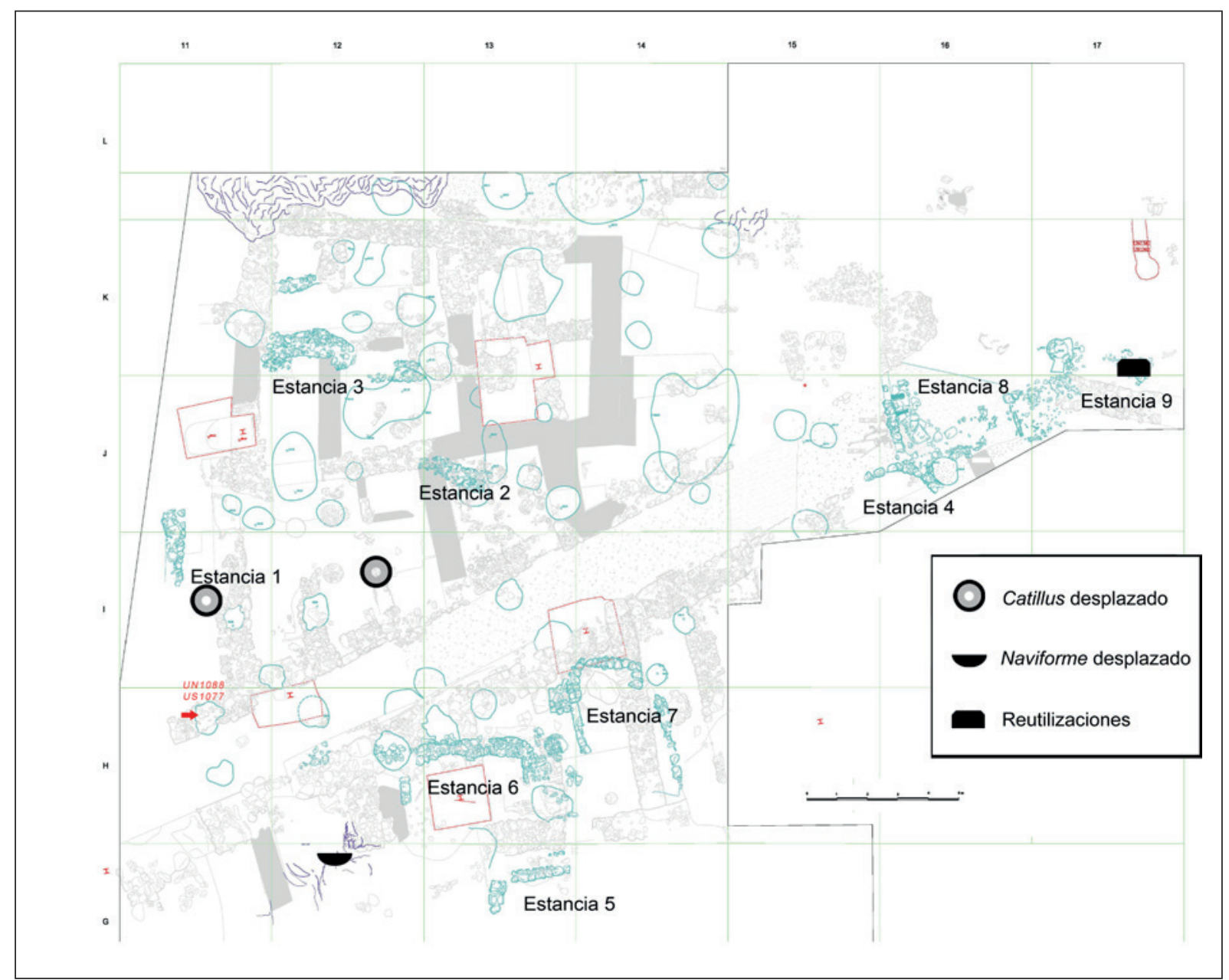

Figura 19 Plano de la fase medieval emiral del Cerro de la Cruz con indicación de los molinos de esa etapa (tipo F).

Un ejemplo de reutilización de molino en el poblado emiral es su uso a modo de ripio o elemento en un zócalo. Contamos con un caso manifiesto de esta práctica en el muro UC 1380, de cronología emiral, zócalo en sentido sur-norte, de muy mala calidad (fig. 20), en cuyo interior aparece una pieza perforada, parte de un catillus en posición horizontal ( $\mathrm{n}^{\mathrm{o}}$ cat. 28 ) (fig. 20). Se trata de una pieza plana probablemente medieval (tipo F), aunque pudiera también ser romana (tipo E). En este caso la pieza aparece incompleta, por lo que podemos suponer que su uso arquitectónico sucedió a su rotura accidental.

Es también un ejemplo de reutilización el caso de la pieza de molino $\mathrm{n}^{\mathrm{o}} 30$, en este caso de origen ibérico, pero que se halló formando parte del paramento del muro 54 (estancia $\mathrm{AB}$ ), de cronología emiral, construido sobre la entrada de la puerta de carros de la estancia ibérica AB (fig 11) (Vaquerizo et al. 1991: 183).
Las fechas de los mejores paralelos para los molinos de época andalusí son pues coincidentes con la fecha que hemos propuesto para la fase medieval del Cerro de la Cruz, en época de la revuelta andalusí de Ibn-Hafsún (Quesada et al. 2012).

\section{CONCLUSIONES}

La catalogación, clasificación tipológica, análisis y trabajo comparativo de un número sustancial de molinos hallados en contexto de excavación arqueológica en el yacimiento del Cerro de la Cruz (Almedinilla, Córdoba) es en sí misma una aportación sustancial al conocimiento de este tipo de objetos de evidente importancia económica. Relativamente bien estudiados para los contextos de la edad del hierro ibérica, sobre 


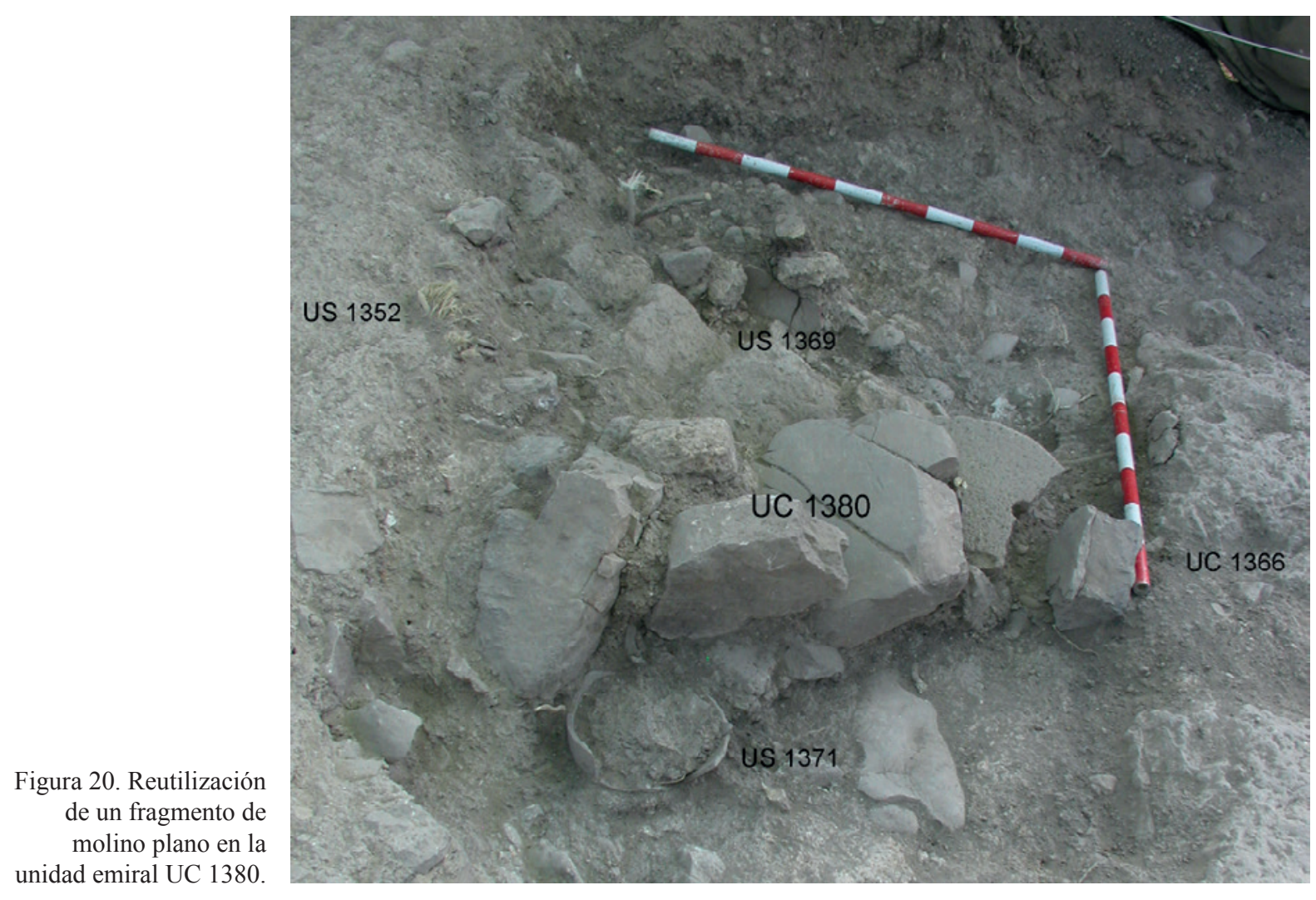

todo en Cataluña, Levante y Extremadura, resulta llamativa la ausencia de estudios comparables en Andalucía, ausencia explicable entre otras cosas por la escasez de excavaciones en extensión de hábitats de época ibérica.

Se han definido hasta seis tipos de molinos rotatorios, con sus variantes, y analizado sus materiales, dimensiones y empleo. Creemos que, aunque por su gran tamaño muchos de estos tipos han sido considerados como 'de sangre', en el contexto de las plataformas bajas del Cerro de la Cruz deben ser considerados como de rotación manual en posición arrodillada, sentada o acuclillada.

Probamos la coexistencia de molinos de vaivén (raros) y rotatorios incluso en fecha tan tardía como la de la destrucción del poblado ibérico, hacia el 141 a.C. Defendemos la posibilidad de que algunos de los molinos se ubicaran en patios o porches, pero también en azoteas y plantas altas, y que en parte sirvieran a una molienda suprafamiliar. Algunos de los molinos del poblado ibérico estaban en uso en el momento de su destrucción, y otros almacenados. Alguno incluso estaba retocado y reutilizado para otras funciones.
Se analiza también la evidencia de los granos que se molían, enfatizando la aparición de leguminosa como el yero junto al cereal.

La fase emiral del poblado, separada por un milenio de la etapa ibérica, ha proporcionado también algunos molinos rotatorios de tipología en general todavía insuficientemente conocida, y en algunos casos similar a modelos de época romana.

\section{Agradecimientos}

Este trabajo se ha realizado en el marco del Proyecto 'Estudio Arqueológico de la Comarca de Almedinilla' financiado por el Excmo. Ayuntamiento de Almedinilla y en el marco de un convenio entre dicha entidad y la Universidad Autónoma de Madrid (Proyecto Código 039500). Queremos agradecer a Timothy Anderson sus comentarios y sugerencias sobre el manuscrito original, aunque por supuesto la responsabilidad de lo escrito recae exclusivamente sobre los firmantes del artículo. Igualmente agradecemos sus detalladas observaciones a los evaluadores anónimos del texto original, cuyas sugerencias hemos incorporado en la casi totalidad de los casos. 


\section{BIBLIOGRAFÍA}

Alonso Martínez, N. (1995): “Les premières meules rotatives manuelles dans le nord de la Péninsule Ibérique", en M.C. Amouretti y G. Comet (eds.), La transmission des connaisances techniques, Table Ronde. Cahiers d'Histoire des Techniques 3: 15-47. Aix en-Provence (1993), Aix-en-Provence, Publications de l'Université de Provence.

Alonso Martínez, N. (1996): "Els molins rotatius: origen i expansió en la Mediterrània occidental". Revista de Arqueologia de Ponent 6: 183-198.

Alonso Martínez, N. (1997): “Origen y expansión del molino rotativo bajo en el Mediterráneo Occidental", en D. García y D. Meeks (coords.), Techniques et économie antiques et médievales. Le temps de l'innovation: 15-19. Paris, Errance.

Alonso Martínez, N. (1999): De la llavor a la farina: els processos agrícoles protohistòrics a la Catalunya Occidental, MAM 4. Lattes, Association pour la recherche archeologique en Languedoc oriental.

Alonso Martínez, N. (2000): "La agricultura de la primer edad del hierro y de época ibérica en el llano occidental catalán: problemática y nuevas aportaciones", en R. Buxó y E. Pons (eds.), Els productes alimentaris d'origen vegetal a l'edat del ferro en l'Europa occidental: de la producción al consum (XXII Col.loqui $A F E A F)$ : 127-138. Girona, Generalitat de Catalunya.

Alonso Martínez, N. (2004): "La transformació dels productes vegetals: la mòlta", en R. Buxó (dir), Eines $i$ feines al camp a Catalunya. L'estudi de l'agricultura a través de l'arqueologia: 112-183. Girona, Generalitat de Catalunya.

Amouretti, M. C. (1986): Le pain et l'huile dans la Grèce Antique. Annales litteraires de l'Université de Besançon, 326. París, Les Belles Lettres.

Anderson, T. (2011): "Los molinos rotatorios de Priego de Córdoba". Informe inédito. LARHRA- CNRS UMR 5190. Museo Arqueológico Municipal de Priego de Córdoba, reg. 2013.

Aragoneses, M. J. (1964-65): “Dos nuevas necrópolis ibéricas en la provincia de Murcia". Anales de la Universidad de Murcia. Filosofía y Letras XXIII (1- 2): 79-90.

Arnanz, A. M. (2000): "Las leguminosas del Cerro de la Cruz (Almedinilla, Córdoba). Presencia de vicia stativa y L. vicia ervilia (1.) willd. en un contexto ibérico". Complutum 11: 239-243.

Arribas Palau, A. (1987): El Barco de El Séc: estudio de los materiales. Mallorca, Universidad de las Islas Baleares.
Arteaga, O.; Padró, J. y Sanmartí, E. (1990): El poblado ibérico del Tossal del Moro de les Pinyeres (Batea, Terra Alta, Tarragona). Monografies Arqueológiques 7. Barcelona, Diputació.

Asensio, D.; Belarte, M.C.; Sanmartí, J. y Santacana, J. (2000-2001): "Les meules rotatives du site ibérique d'Alorda Park (Calafell, Baix Penedés, Tarragona)". Pyrenae 31-32: 57-73.

Berrocal Rangel, L. (2006): "De la mecánica a la molienda: un ensayo sobre los molinos giratorios de la España antigua”, en J. Blánquez, L. Roldán y H. Vialás (eds.), Augusto Fernández de Avilés. En homenaje, Serie Varia 6: 275-297. Madrid, Universidad Autónoma.

Bonet Rosado, H. (1995): El Tossal de Sant Miquel de Liria: la antigua Edeta y su territorio. Valencia, Diputación de Valencia.

Bonet Rosado, H. y Mata Parreño, C. (2002): El Puntal dels Llops: un fortín edetano. Valencia, Diputación de Valencia.

Borges, N. (1978): "Mós manuais de Conimbriga". Conimbriga 17: 115-140.

Bosch-Gimpera, P. (1915-1920): "Les investigacions de la cultura ibérica al Baix Aragó". Anuario de l'Institut d'Estudis Catalans X: 641-670.

Boyer, F. y Buchsenschutz, O. (1998): "Les conditions d'une interprétation fonctionnelle des moulins "celtiques" rotatifs à mains sont-elles réunies? / Are the conditions united for a functional interpretation of the "celtic " hand-turned rotary mills?". Revue archéologique du Centre de la France 37: 197-206.

Burillo Mozota, F. (1982): "El urbanismo del poblado ibérico de El Taratrato de Alcañiz”. Kalathos 2: 47-66.

Camañes Villagrasa, M. P. (2010a): "Estudio funcional de los espacios de Molí d'Espigol (Tornabous, L'Urgell): transformación, elaboración y consumo de alimentos". Cypsela 18: 193-208.

Camañes Villagrasa, M. P. (2010b): "Espacios de elaboración y consumo de alimentos en el asentamiento ibérico de Molí d'Espigol". Saguntum Extra 9: 183-188.

Carmona, R. (2010): “Aproximación arqueológica al territorio del rebelde muladí Ibn Mastana (s. IX d.C.) en la comarca de madinat baguh (Priego de Córdoba)". Antiqvitas 22: 141-157.

Castella, D. y Anderson, T. (2004): "Les meules du Musée Romain d'Avenches». Bulletin de l'Associaton Pro Aventico 46: 115-169.

Checa, A.; Jimeno, A.; Tresserras, J.J.; Benito, J.P. y Sanz, A. (1999): "Molienda y economía doméstica en Numancia”, en F. Burillo (coord.), Simposio 
sobre los Celtíberos (4. 1997. Daroca): 63-68. Valencia, Diputación de Valencia.

Escalera, J. y Villegas, A. (1983): Molinos y panaderías tradicionales. Madrid, Editora Nacional.

Espí Pérez, I.; Grau Mira, I.; López Seguí, E. y Torregrosa Giménez, P. (2009): “La aldea ibérica de l'Alt del Punxó. Poducción agrícola y asentamiento campesino en el área central de la Contestania”. $L v$ centvm 28: 23-50.

Fletcher, D.; Pla, E. y Alcácer, J. (1965): La Bastida de Les Alcusses. Series de Trabajos Varios 24. Valencia, Diputación de Valencia.

Flors Ureña, E. (coord.) (2009): Torre la Sal (Ribera de Cabanes, Castellón): Evolución del paisaje antrópico desde la Prehistoria hasta el Medioevo. Monografíes de Prehistòria i arqueología castellonenques, 8. Castelló, Diputació.

Fuertes Prieto, M. N. y PÉREZ ORTIZ, L. (2008): “Material lítico tallado y pulimentado de yacimiento de la Edad de Hierro en la Meseta Oriental leonesa. La comarca de los Oteros". Férvedes 7: 247-256.

Genis Armada, M. T. (1985): "Els objectes lítics ibèrics d'Ullastret i Puig Castellet”. Cypsela 5: 107-124.

Genis Armada, M. T. (1986): “Cap a una tipología dels molins d'epoca ibérica a Ullastret". Faventia: Revista de filología clàssica 8: 99-116.

Gómez, E. (2000): Les mortiers de cuisine en Languedoc (VIe-IVe siècle av. J.C.). Girona, Monografíes del MAC.

González del Campo, E. (2010): “La aldea de época emiral del Cerro de la Cruz. Una aproximación a su arquitectura y cultura material". Oikos 2: 125-140.

González Salas, S. (1945): El castro de Yecla en Sto. Domingo de Silos, Burgos (Informes y Memorias 7). Madrid, Ministerio de Educación Nacional.

Gudea, N. (1997): "Römischen Drehmühlen von Porolissum und auch den Kastellen des westlichen Limes der provinz Dacia Porolissensis". Acta Musei Napocensis 34: 229-234.

Guérin, P. (1999): "Hogares, molinos, telares... El Castellet de Bernabé y sus ocupantes". Arqueología espacial 21: 85-89.

Gutierrez Lloret, S. (1996a): "La producción de pan y aceite en ambientes domésticos. Límites y posibilidades de una aproximación etno-arqueológica". Arqueología medieval 4: 237-255.

Gutierrez Lloret, S. (1996b): La Cora de Tudmir: de la Antigüedad Tardía al mundo islámico. Poblamiento y cultura material. Alicante, Diputación Provincial.

Iborra, P.; Mata, C.; Moreno, A.; Pérez, G.; Quixal, D.; Vives-Ferrándiz, J. (2010): "Prácticas culinarias y alimentación en asentamientos ibéricos valencianos", en C. Mata, G. Pérez y J. Vives-Ferrándiz (eds.), De la cuina a la taula IV reunió d'economia en el primer milenni a.C.: 99-114. SAGVNTVM EXTRA-9. Valencia, Universidad de Valencia.

Izquierdo Benito, R. (1979): "Excavaciones en la ciudad hispano-musulmana de Vascos, Navalmoralejo, Toledo. Campañas de 1979-1980". Noticiario Arqueológico Hispánico 16: 248-392.

Jaccottey, L. y Farget, V. (2011) "Les normes de dessin des meules rotatives", en O. Buchsenschutz, L. Jaccotey, F. Jodry y J.L. Blanchared (eds.), Evolution typologique et technique des meules du Néolithique à l'an mille, Aquitania, Suppl. 23: 51-68. Saint-Julien-sur-Garonne, Editions de la Fédération Aquitania.

Junyent, E. y Baldellou, V. (1972): "Estudio de una casa ibérica en el poblado de "Mas Boscà", Badalona (provincia de Barcelona)". Principe de Viana 126-127: 5-68.

Longepierre, S. (2012): Meules, moulins et meulières en Gaule méridionale du IIe s. av. J.-C. au VIIe s. ap. J.-C. Monographies Instrumentum 41. Montagnac, Eds. Monique Mergoil.

López i Reyes, D.; Buxó i Capdevila, R.; García i Rubert, D. y Moreno Martínez, I. (2011): "Noves aportacions sobre agricultura i alimentació durant la primera edat del ferro a Catalunya: dades de l'assentament de Sant Jaume (Alcanar, Montsià)". Pyrenae 42: 77-118.

Mederos Martín, A. y Escribano Cobo, G. (2001): “El comercio de los molinos rotatorios romanos en el mediterráneo y litoral atlántico norteafricano". Archivo de Prehistoria Levantina XXIV: 315-331.

Moritz, L.A. (1958): Grain-mills and flour in classical antiquity. Oxford, Clarendon Press.

Motos Guirao, E. (1991): El poblado medieval del Castillón. Montefrio, Granada. Granada, Universidad de Granada.

Oliver, A. y Gusi, F. (1995) El Puig de la Nau. Monografies de Prehistoria. Castellón, Diputación de Castellón.

Pérez Jordà, G.; Iborra, M. P.; Grau, E.; Bonet, H. y Mata, C. (2000): "La explotación agraria del territorio en época ibérica: los casos de Edeta y Kelin." Sèrie Monogràfica 18: 151-167. Girona, Museu d'Arqueología de Catalunya.

Pérez-Jordá, G.; Morales Pérez, J. V.; Marlasca Martín, R.; Gómez Bellard, C. y Van Dommelen, P. (2010): "La alimentación en una granja púnica de Cerdeña”. Sagvntvm Extra 9: 295-302. 
Pons i Brun, E. y Llorens i Rams, J.M. (1991): "L'organitzaió de l'espai domestic a Puig Castellet. Lloret de Mar-la-Selva". Cypsela IX: 95-110.

Pons, E.; Fernández, M. J.; González, H.; Gago, N. y Bouso, M. (2000): "El establecimiento agrario de Mas Castellar de Pontós (s. III-II a.C.)", en R. Buxó y E. Pons (dirs.), L'Habitat protohistoric a Catalunya, Roselló i Llenguadoc Occidental. Actualitat de l'Arqueologia de l'Edat del Ferro: 147-159. Girona, Museu d 'Arqueologia de Catalunya.

Pons Brun, E. y García Petit, L. (2008): Prácticas alimentarias en el mundo ibérico. El ejemplo de la fosa FS362 de Más Castellar de Pontós (EmpordáEspaña). B.A.R. International Series 1753. Oxford, British Archaeological Reports.

Py, M. (1992): "Meules d'epoque protohistorique et romaine provenant de Lattes", en M. Py (dir.), Recherches sur l'economie vivrière des lettarenses. Lattara 5: 183-232.

Quesada Sanz, F.; Kavanagh de Prado, E. y Moralejo Ordax, J. (2010): "El asentamiento de época ibérica en el Cerro de la Cruz”, en I. Muñíz Jaén y F. Quesada Sanz (eds.), Oikos. Un drama en tres actos. Dos milenios de ocupacion humana en el Cerro de la Cruz (Almedinilla, Córdoba): 75-95. Córdoba, Ayto. de Almedinilla.

Quesada Sanz, F.; Muñiz Jaén, I.; Kavanagh de Prado, E.; Moralejo Ordax, J. y Martínez Sánchez, R. (2012): "La ocupación de época emiral islámica del Cerro de la Cruz (Almedinilla, Córdoba): Análisis de un contexto representativo: la fosa UN 1088/US 1077". Antiquitas 24: 203-221.

Quesada Sanz, F.; Muñiz Jaén, I. y López Flores, I. (2013): "La guerre et ses traces: destruction et massacre dans le village ibérique du Cerro de la Cruz (Córdoba) et leur contexte historique au IIe s. av. J.C. ", en M. Navarro y F. Cadiou (eds.), La guerre et ses traces: 25-53. Burdeos (2011), Burdeos, e.p.

Reille, J.L. (2000): 'L'apparition des meules rotatives en Languedoc oriental (IVe s. avant J.C) d'après l'etude du site de Lattes". Gallia 57: 261-271.

Reille, J.L. (2000): “Agde et le commerce des meules à grains en Gaule Méditerranéenne á la fin de l'Âge du Fer (IIe-Ier siècles av. N. È.)", en E. Pons, R.
Buxó y J.L. Reille (eds.), Els productes alimentaris d'origen vegetal a l'edat del ferro de l'Europa Occidental : de la producció al consum: 361-365. Girona (1998), Girona, Museu d'Arqueología de Catalunya.

Risch, R. (1995): Recursos naturales y sistemas de producción en la Península Ibérica entre 3000 y 1000 a.n.e. (Tesis Doctoral Universidad Autónoma de Barcelona) (http://www.tdx.cat/ handle/10803/5524).

Robert, B. y Landreat, J.L. (2005): "Meules rotatives a calcaire. Les meules rotatives en calcaire à glauconie grossière et l'atelier de Vauxrezis (Aisne). Un état de la question". Revue archéologique de Picardie. Numéro spécial 22: 105-114.

Rodríguez Díaz, A. (ed.) (2004) El edificio protohistórico de 'La Mata' (Campanario, Badajoz) y su estudio territorial. 2 vols. Cáceres, Universidad de Extremadura.

Runnels, C. (1990): “Rotatory querns in Greece”. Journal of Roman Archaeology 3: 147-154.

Sanmartí, J., Gili, E., Rigo, A., De La Pinta, J. L. (1992): Els primers pobladors de Sta Coloma de Gramenet, dels orígens al món romà. Santa Coloma de Gramenet, Museu Torre Balldovina.

Vaquerizo Gil, D. (1990) El yacimiento ibérico del Cerro de la Cruz (Almedinilla, Córdoba). Córdoba, Diputación Provincial.

Vaquerizo, D.; Quesada, F. y Murillo, J. F. (1991): "Avance al estudio de los materiales arqueológicos recuperados en el Cerro de la Cruz". Anales de Arqueología Cordobesa 2: 171-224.

Vaquerizo, D.; Quesada, F. y Murillo, J. F. (1994): "Unidades de hábitat y técnicas constructivas en el yacimiento ibérico del Cerro de la Cruz". Anales de Arqueología Cordobesa 5: 61-97.

Vaquerizo Gil, D.; Quesada Sanz, F. y Murillo Redondo, J. F. (2001): Protohistoria y romanización en la subbética cordobesa. Aproximación al desarrollo de la cultura ibérica. Córdoba, Universidad de Córdoba.

Wright, K. (1992): “A Classification System for Ground Stone Tools from the Prehistoric Levant". Paléorient 18(2): 53-81. 